\title{
Labor Market Performance Effects of Discrimination and Loss of Skill
}

\author{
Larsen, Birthe; Waisman, Gisela
}

\author{
Document Version \\ Published in: \\ Economic Inquiry \\ DOI: \\ 10.1111/ecin. 12335 \\ Publication date: \\ 2016 \\ License \\ Unspecified
}

Accepted author manuscript

Citation for published version (APA):

Larsen, B., \& Waisman, G. (2016). Labor Market Performance Effects of Discrimination and Loss of Skill. Economic Inquiry, 54(3), 1574-1595. https://doi.org/10.1111/ecin.12335

Link to publication in CBS Research Portal

\section{General rights}

Copyright and moral rights for the publications made accessible in the public portal are retained by the authors and/or other copyright owners and it is a condition of accessing publications that users recognise and abide by the legal requirements associated with these rights.

\section{Take down policy}

If you believe that this document breaches copyright please contact us (research.lib@cbs.dk) providing details, and we will remove access to the work immediately and investigate your claim.

Download date: 26. Apr. 2023

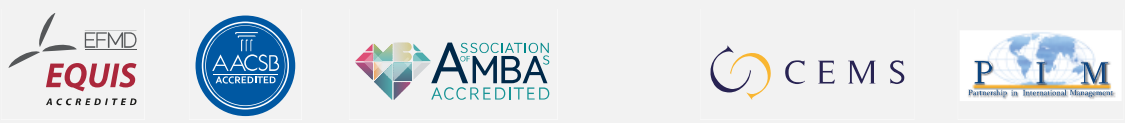




\section{Labor Market Performance Effects of Discrimination and Loss of Skill}

\section{Birthe Larsen and Gisela Waisman}

Journal article (Post print version)

This is the peer reviewed version of the following article: Labor Market Performance

Effects of Discrimination and Loss of Skill. / Larsen, Birthe; Waisman, Gisela. In: Economic Inquiry, Vol. 54, No. 3, 2016, p. 1574-1595, which has been published in final form at http://dx.doi.org/10.1111/ecin.12335.

This article may be used for non-commercial purposes in accordance with Wiley

Terms and Conditions for Self-Archiving.

Uploaded to Research@CBS: July २०16 


\title{
LABOUR MARKET PERFORMANCE EFFECTS OF DISCRIMINATION AND LOSS OF SKILL
}

\author{
Birthe Larsen, Gisela Waisman. ${ }^{\ddagger}$
}

January 19, 2016

\begin{abstract}
We examine the impact of discrimination on labour market performance when workers are subject to a risk of losing skills during an unemployment experience. Within a search and matching framework, we show that both natives and immigrants are affected by discrimination. Discrimination in one sector has positive spillovers, inducing employment to increase in the other sector and the effect on labour market performance therefore depends on whether discrimination is present in only one sector or in both. Discrimination may induce workers to train more or less than natives after having lost their skills, dependent upon in which sector there is discrimination. Net output tends to be most negatively affected by discrimination among high-skilled workers.
\end{abstract}

Keywords: discrimination, unemployment, search and matching, wages.

JEL classifications: J15, J31, J61, J64, J71

\section{INTRODUCTION}

Several studies have found that the terrorist attacks of September 11, 2001 had effects on the USA labour market outcomes of individuals with country of origin profiles similar to those of the terrorists. ${ }^{1}$ Similarly, Zussman (2010) finds that ethnic bias in judicial decision-making in Israel depends on the number of fatalities from recent attacks in the vicinity of the court but not in other places. Discrimination can be a reaction to external events where none of the parties are involved. It is yet to been seen whether the recent attacks in Paris and Copenhagen will have a similar impact on the labour market.

This paper considers the impact of discrimination on labour market performance for both natives and immigrants. We are interested in the impact on wages and unemployment for different skill levels and ethnicities as well as the effect on training.

The novelty of this paper is to study the effects of discrimination of immigrants on labour market performance taking into account that workers risk losing skills during an unemployment spell and that firms supplying vacancies to any high or low productivity worker, not distinguishing by ethnicity, are potentially affected by discrimination. ${ }^{2}$ The underlying issue is that the impact of discrimination is potentially amplified if workers are subject to the risk of

\footnotetext{
*Department of Economics, Copenhagen Business School.

†Sulcis, Stockholm University and Finansdepartementet, Stockholm.

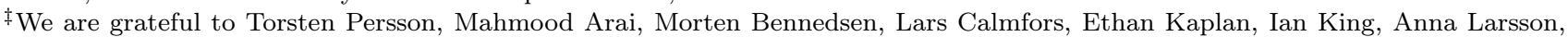
Åsa Rosén, Lise Duedal Vesterlund, Fabrizio Zilibotti and seminar participants at the IIES, Copenhagen Business School, University of Melbourne, The Nordic Workshop, Sønderborg 2008, EEA-ESEM Milan 2008, and EALE Amsterdam 2008 for helpful comments, to Christina Lönnblad for editorial assistance and to Insead for their hospitality, to Patrick Bennett and Simon Backlund for excellent research assistance as well as two anonymous referees. Any errors are our own.

${ }^{1}$ Davila and Mora (2005), Kaushal, Kaestner, and Reimers (2007), Rabby and Rodgers (2011) etc.

${ }^{2}$ Larsen (2001) has a similar set-up, but does not distinguish by origin.
} 
losing skills during their unemployment spell. Discrimination may not only result in natives and immigrants getting different pay for the same work, but also in workers with similar skill levels ending up in different occupations.

Following the empirical literature mentioned above, we model discrimination as a capricious rejection of immigrant applicants. Negative events, such as unexpected violent political or religious motivated developments, trigger these rejections. After a trigger event, an immigrant worker does not get a job offer, while a native worker does. In the model we assume that unemployed workers who lose their skills only can search for jobs in the low-productivity sector. ${ }^{3}$ Low-skilled workers may regain their skills through training when unemployed.

Empirical evidence supports the fact that employment below an individual's qualifications, in terms of educational level, and loss of skill are important issues to consider. First, Arai et al (2000) show that the probability of getting a qualified job is $70 \%$ lower for immigrants to Sweden born in Eastern Europe, Asia or Africa, and 50\% lower for those born in Latin America, than for similar natives. Immigrants are overrepresented in only three out of 29 occupations, all of which require no education or training. Second, Reitz (2001) shows that the under-utilization of immigrant skills is significant in Canada. Finally, Nielsen et al (2004) show that a large fraction of the wage gap between immigrants and natives in Denmark would disappear if immigrants could accumulate work experience.

This paper focuses on wages and unemployment and we therefore consider a search and matching framework, which allows vacancy supply to be affected by discrimination. The model is along the lines of Pissarides (2000), combined with an endogenous skill choice. Acemoglu (2001) and Albrecht and Vroman (2002) model the choice of skill requirements by firms, while we consider the decision taken by workers. In Burdett and Smith (2002) and Aricó (2009), workers with heterogeneous training costs take an investment decision in skill-acquisition before entering the job market, while we allow for training in any instance a worker loses skills. None of these papers study the issue of discrimination. Bowlus and Eckstein (2002), Flabbi (2010), Mailath et al. (2000), and Lang et al. (2005) study racial and gender discrimination in the presence of search frictions, but without loss of skill. Our paper relates also to a literature that analyses the direct effects of immigration in models with a labour market characterized by search and matching. None of these papers deal explicitly with the issue of discrimination. Liu (2010) explores the macroeconomic and welfare effects of illegal immigration on the native born within a dynamic general equilibrium framework with labour market frictions allowing for heterogeneity in skills. Battisti et al (2015) study the effects of immigration on native welfare in a general equilibrium model featuring skill heterogeneity, search frictions, wage bargaining and a redistributive welfare state. Chassamboulli \& Palivos (2013) and (2014) analyse the impact of the immigration influx on labour market outcomes within a search and matching framework in Greece and USA respectively. Chassamboulli and Peri (2014) use a similar model to analyse the issue of how to deal with undocumented workers and the effect that different policies have on job creation. In their model, legalization stimulates firms' job creation by increasing the total number of immigrants and stimulating firms to post more vacancies some of which are filled by natives.

The paper is organized as follows. First, in Section 2 we set up a simple two sector model without loss of skill and investigate the impact of discrimination on labour market performance. We show that if there is only discrimination in the low-skilled sector, both native and immigrant workers in this sector are negatively affected both in terms of reduced wages and higher unemployment, whereas high-skilled workers are unaffected. With equal discrimination in the two sectors, all workers are negatively affected in terms of lower wages and higher unemployment, where the impact is larger on high-skilled workers than low-skilled workers. We then extend the model to include a risk of losing skills and the opportunity of exogenous training while unemployed. In this case, discrimination in one skill sector affects the other sector. In case of discrimination in the low-skilled sector, the employment prospects of the highskilled workers improve, whereas in case of discrimination in both sectors, high-skilled workers are unambigously

\footnotetext{
${ }^{3}$ For simplicity, we disregard self-employment.
} 
worse off, while the impact on labour market performance for low-skilled workers is ambiguous. Finally, in Section 4, we include endogenous training, and show that higher discrimination in the low-skilled sector increases training of all workers, but the impact is stronger for immigrants. The proportion of high-skilled immigrants then becomes higher than the proportion of high-skilled natives, despite the fact that more immigrants tend to become low-skilled workers, that is, more of them lose skills. This is the case as the higher fraction of immigrants than natives training more than compensates for the negative impact on immigrants' skill level through loss of skill. Section 5 brings an evaluation of the impact of discrimination on net output, where we show that the negative impact on net output is the stronger when discrimination exists in the high-skilled sector compared to when it exists only in the low-skilled sector. Section 6 includes simulations and Section 7 concludes.

\section{A SIMPLE MODEL WITHOUT LOSS OF SKILLS}

We develop a two sector equilibrium search and matching model where firms and workers are risk-neutral and infinitely lived. The economy is populated by native, $n$, and immigrant workers, $1-n$, which are exogenously given. The labour force is normalized to one.

Firms in sector $h$ require skilled workers with productivity $y_{h}$, while firms in sector $l$ employ workers with productivity $y_{l}$, where $y_{l}<y_{h}$. Due to legal issues, firms may not direct vacancy supply towards natives only. In this first simple version of the model, a fraction $\xi$ of the native and immigrant workers will be high-skilled and the rest, $1-\xi$, will be low-skilled workers.

We model discrimination as a capricious rejection of immigrant applicants. If a negative external event, such as media portraying immigrants in a negative manner, occurs after a vacancy was opened but prior to a match with an immigrant worker, the immigrant is not offered a job. In this way, discrimination implies that immigrants face a lower probability of getting a job than natives. This occurs in a match with probability $d_{s}, s=h, l .{ }^{4}$

\section{$2.1 \quad$ Matching}

Unemployed high-productivity workers search for jobs in sector $h$ and low productivity workers search in sector $l$. Productivity is sector specific. We assume that the value of skilled unemployment is higher than the value of unskilled employment, implying it is not optimal for high-skilled workers to search for low-skilled jobs. ${ }^{5}$

The matching function for sector $s$ is assumed to have the functional form $v_{s}^{\alpha} u_{s}^{1-\alpha}$ where $v_{s}$ is the sectorial vacancy rate and $u_{s}$ is the unemployment rate in sector $s=h, l$ and $0<\alpha<1$. The transition rate into employment for a native worker with productivity $s$ is given by $f_{s}^{N}=f\left(\theta_{s}\right)=\theta_{s}^{\alpha}, s=h, l$ where $\theta_{s}=v_{s} / u_{s}$ captures sectorial labour market tightness. As discrimination may disrupt a match, the immigrant workers' transition rates into employment are reduced relative to those of natives to $f_{s}^{I}=f\left(\theta_{s}\right)\left(1-d_{s}\right)=\theta_{s}^{\alpha}\left(1-d_{s}\right), s=h, l$. The firm flow arrival rate is $q_{s}=\theta_{s}^{\alpha-1}, s=h, l$.

\subsection{Workers}

The present discounted value of an unemployed worker of skill level $s=h, l$ and origin $J=N, I$ (natives or immigrants) is given by

$$
\rho U_{s}^{J}=f_{s}^{J}\left(W_{s}^{J}-U_{s}^{J}\right), J=N, I, s=h, l,
$$

\footnotetext{
${ }^{4}$ An alternative is to model discrimination on exit, where an immigrant worker is either fired or forced to resign with a higher probability than a native worker. This alternative set up delivers results similar to those in our model.

${ }^{5} \mathrm{~A}$ sufficient condition requires that the difference in productivities is sufficiently large $y_{h} / y_{l}>1.25$ and unemployment smaller than employment. See Appendix 1a for details.
} 
where $\rho$ is the discount rate. At the flow arrival rate $f_{s}^{J}$ the worker gets a job and receives the value $W_{s}^{J}$, which satisfies

$$
\rho W_{s}^{J}=w_{s}^{J}+\sigma\left(U_{s}^{J}-W_{s}^{J}\right), J=N, I, s=h, l,
$$

where $w_{s}^{J}$ is the wage in sector $s$ for natives, $J=N$, or immigrants, $J=I$, and $\sigma$ is job separation, which is assumed to be exogenous and identical for both sectors and for natives and immigrants. All parameter values are common knowledge.

\section{$2.3 \quad$ Firms}

The present discounted value of opening a vacancy in sector $s$ is

$$
\rho V_{s}^{J}=q_{s}\left(\phi_{s}\left(X_{s}^{N}-V_{s}^{N}\right)+\left(1-\phi_{s}\right)\left(1-d_{s}\right)\left(X_{s}^{I}-V_{s}^{I}\right)\right)-k, \quad s=h, l,
$$

where $\phi_{s}$ is the proportion of natives among the unemployed workers of productivity $s$ and $k$ is the flow costs of maintaining an open vacancy. At the rate $q_{s} \phi_{s}$ the vacancy is filled with a native worker which provides a value $X_{s}^{N}$ to the firm, and at the rate $q_{s}\left(1-\phi_{s}\right)\left(1-d_{s}\right)$ the vacancy is filled with an immigrant creating the value $X_{s}^{I}$. The present discounted value of a job in sector $s$ occupied by a worker of origin $J$ satisfies

$$
\rho X_{s}^{J}=y_{s}-w_{s}^{J}+\sigma\left(V_{s}^{J}-X_{s}^{J}\right), J=N, I, s=h, l .
$$

Using (3), (4), the matching function and assuming free entry, $V_{s}=0$, we obtain two equations which determine labour market tightness, $\theta_{s}, s=h, l$ :

$$
k \theta_{s}^{1-\alpha}(\rho+\sigma)-\phi_{s}\left(y_{s}-w_{s}^{N}\right)-\left(1-\phi_{s}\right)\left(1-d_{s}\right)\left(y_{s}-w_{s}^{I}\right)=0, \quad s=h, l .
$$

For given wages, discrimination has a relative large negative impact on the value of supplying a vacancy when the pool of unemployed immigrants is relatively high, that is, when $\phi_{s}$ is small.

\subsection{Wage Determination}

Wages are determined by Nash Bargaining with equal bargaining power for worker and firm, resulting in the first order conditions: $X_{s}^{J}=W_{s}^{J}-U_{s}^{J}, s=h, l, J=N, I$, where we have imposed symmetry and the free entry condition, $V_{s}=0, s=h, l$. Substituting for equations (1)-(4) gives the equilibrium wages, $w_{s}^{J}$ :

$$
w_{s}^{J}=\frac{\rho+\sigma+f_{s}^{J}}{2(\rho+\sigma)+f_{s}^{J}} y_{s}, J=N, I, s=h, l .
$$

When discrimination is relatively high, this tends to reduce the fraction of native workers among the unemployed, $\phi_{s}$, and therefore diminish the expected value of supplying a vacancy which lowers labour market tightness. We determine $\phi_{s}$ below, which allows us to determine the relative size of high-skilled and low-skilled workers' transition rate. Due to discrimination, immigrants experience a lower transition rate than natives, and due to this, natives receive higher wages than immigrants, $w_{s}^{N}>w_{s}^{I}, s=h, l$.

\subsection{Unemployment}

We derive steady state unemployment rates by equalizing the flows into and out of unemployment and by using 
the fact that we assume natives and immigrants are divided into $\xi$ skilled and $(1-\xi)$ low-skilled workers. ${ }^{6}$ The steady state unemployment rates then become:

$$
u_{s}^{J}=\frac{\sigma}{f_{s}^{J}+\sigma}, s=h, l, J=N, I
$$

Discrimination implies that a native worker's transition rate is higher than an immigrant worker's transition rate, $f_{s}^{N}>f_{s}^{I}$ and hence for each skill level, immigrants experience a higher unemployment rate than natives, $u_{s}^{I} / u_{s}^{N}>1, s=h, l$.

The proportion of natives among the unemployed workers of productivity $s=h, l$ is then given by

$$
\phi_{h}=\frac{u_{h}^{N} \xi n}{u_{h}^{N} \xi n+u_{h}^{I} \xi(1-n)}=\frac{1}{1+\frac{1-n}{n}\left(u_{h}^{I} / u_{h}^{N}\right)}, \phi_{l}=\frac{u_{l}^{N}(1-\xi) n}{u_{l}^{N}(1-\xi) n+u_{l}^{I}(1-\xi)(1-n)}=\frac{1}{1+\frac{1-n}{n}\left(u_{l}^{I} / u_{l}^{N}\right)} .
$$

\subsection{Labour Market Tightness}

Labour market tightness for the skilled sector and low-skilled sector is determined by inserting wages from equation (6) into equation (5):

$$
k \theta_{s}^{1-\alpha}-\phi_{s} \frac{y_{s}}{2(\rho+\sigma)+\theta_{s}^{\alpha}}-\left(1-\phi_{s}\right) \frac{y_{s}\left(1-d_{s}\right)}{2(\rho+\sigma)+\theta_{s}^{\alpha}\left(1-d_{s}\right)}=0, \quad s=h, l .
$$

Comparing the values of labour market tightness in the high-skilled and low-skilled sectors, we obtain the following: as productivity is higher for high-skilled workers than for low-skilled workers, this tends to increase labour market tightness in the skilled sector relative to the low-skilled sector. However, discrimination also affects the expected profitability of supplying a vacancy and, therefore, the vacancy supply. In the first case, when there is no discrimination for skilled workers, $d_{l}>0, d_{h}=0$, supplying vacancies toward low-skilled workers is even less profitable, and labour market tightness is higher for skilled workers than for low-skilled workers, $\theta_{h}>\theta_{l}$. This results in a higher transition rate for high-skilled workers than for low-skilled workers, $f_{h}>f_{l}$. In the second case, where $d_{h}=d_{l}=d>0$, labour market tightness in the high-skilled sector is higher than labour market tightness in the low-skilled sector, provided discrimination is not too high. ${ }^{7}$ Hence, when discrimination is not too high we obtain that $\theta_{h}>\theta_{l}$. The result is $f_{h}>f_{l}, w_{h}^{J}>w_{l}^{J}, J=N, I$ and high-skilled workers experience a lower unemployment rate than low-skilled workers.

\subsection{No Loss of Skill and Higher Discrimination}

In this section, we examine the impact on labour market performance due to an increase in discrimination. We consider two different cases. In the first case, discrimination is only present in the low-skilled sector and in the second, discrimination is present at an equal level in both sectors. Discrimination against immigrants implies that it takes longer for firms to fill vacancies, which reduces the expected profits from opening vacancies, and in turn vacancy creation. Furthermore, discrimination against immigrants implies that more immigrants remain unemployed. With higher discrimination, the share of immigrants among the unemployed increases and firms are more likely to encounter immigrants instead of native workers. Therefore, it takes longer for firms to fill vacancies, firm profits fall and firms open fewer vacancies per unemployed worker. ${ }^{8}$ In this simple model discrimination in one

\footnotetext{
${ }^{6}$ The flow equilibrium equations are $\sigma e_{h}^{N} \xi n=f_{h}^{N} u_{h}^{N} \xi n, \sigma e_{l}^{N}(1-\xi) n=f_{l}^{N} u_{l}^{N}(1-\xi) n$ and $\sigma e_{h}^{I} \xi(1-n) \quad=$ $f_{h}^{I} u_{h}^{I} \xi(1-n), \sigma e_{l}^{I}(1-\xi)(1-n)=f_{l}^{I} u_{l}^{I}(1-\xi)(1-n)$.

${ }^{7}$ See Larsen and Waisman 2015 for a proof.

8 Proofs of propositions are given by straightforward differentiations of the involved equations.
} 
sector has no impact on the natives belonging to the other sector; that is, the two sectors are independent and only the natives belonging to the sector where discrimination takes place are affected.

\subsubsection{Discrimination of Low-skilled Workers}

When only low-skilled workers are discriminated against, $d_{h}=0, d_{l}>0$, we observe the following.

Proposition: When discrimination is only present in the low-skilled sector, $d_{h}=0, d_{l}>0$, an increase in discrimination reduces labour market tightness in the low-skilled sector, $d \theta_{l} / d d_{l}<0$. Consequently, the low-skilled workers' wages fall and their unemployment rate increases. The reduction of wages and the increase in unemployment is higher for immigrants than natives, $\left|d w_{l}^{N} / d d_{l}\right|<\left|d w_{l}^{I} / d d_{l}\right|, d u_{l}^{N} / d d_{l}<d u_{l}^{I} / d d_{l}$, implying an increase in inequality between natives and immigrants. The proportion of natives among the low-skilled unemployed workers decreases, $d \phi_{l} / d d_{l}<0$ whereas the proportion of natives among the high-skilled workers is unaffected, $d \phi_{h} / d d_{l}=0$. For skilled workers, labour market tightness and thereby the unemployment rates and wages, are also unaffected.

Higher discrimination in the sector employing low-skilled workers has a direct negative impact on labour market tightness for low-skilled workers. The reduction in labour market tightness reduces all low-skilled workers' transition rates and as immigrants are also directly negatively affected, their transition rates fall more than the transition rates of natives. Therefore, the unemployment rate for low-skilled workers increases, again more for immigrants than natives. Finally, the reduction of the transition rate reduces the bargaining position of all low-skilled workers, but more for immigrants than for natives, which implies that all low-skilled wages fall and the negative impact is larger for immigrants than for natives. Hence, inequality between natives and immigrants increases.

As skilled workers are not affected by discrimination, the inequality between high-skilled and low-skilled workers increases, both in terms of wage differences and unemployment rates. Hence, if discrimination is only present in the sector employing low-skilled workers, discrimination increases wage differences between all skilled and all low-skilled workers, for both natives and immigrants, beyond what is due to a pure productivity difference.

\subsubsection{Discrimination of High-skilled and Low-skilled Workers}

In the second case, both skilled and low-skilled workers are discriminated against, $d_{h}=d_{l}=d>0$. In this case we obtain the following around $d_{h}=d_{l}=0$.

Proposition: When discrimination is present in both sectors, that is, $d_{h}=d_{l}=d>0$, an increase in discrimination reduces labour market tightness in both sectors, but the impact on the sector employing skilled workers is the largest, $\left|d \theta_{h} / d d\right|>\left|d \theta_{l} / d d\right|$. All workers' wages fall and their unemployment rate increases. The reduction of wages and the increase in unemployment is larger for immigrants than natives, $\left|d w_{s}^{N} / d d\right|<\left|d w_{s}^{I} / d d\right|, d u_{s}^{N} / d d<d u_{s}^{I} / d d$, implying an increase in inequality between natives and immigrants. The proportion of natives among the unemployed workers decreases, and the negative impact is greater for skilled workers, $\left|d \phi_{h} / d d\right|>\left|d \phi_{l} / d d\right|$, corresponding to a decrease in inequality between high-skilled and low-skilled workers in terms of unemployment rates.

In case two, when discrimination increases by the same amount in both sectors, there is a direct negative impact on labour market tightness for all workers. The reduction in labour market tightness reduces all workers' transition rate and as immigrants are also directly negatively affected, their transition rate falls more so than the transition rate of natives. Therefore, the unemployment rate for low-skilled workers increases, again more for immigrants than natives.

The bargaining position decreases for all workers as their transition rates fall, and the larger decline for immigrants results in lower wages and as the impact on wages is larger for immigrants than for natives, this implies more inequality between natives and immigrants. 


\section{LOSS OF SKILL AND EXOGENOUS TRAINING}

The impact of discrimination is potentially amplified if workers are subject to the risk of losing skills during unemployment. Therefore we include this possibility in our model by allowing for skill loss during periods of unemployment, shifting the worker from being a high-skilled to a low-skilled worker. Unemployed workers who lose their skills can only search for jobs in the low-productivity sector. Low-skilled workers may regain their skills by training when unemployed, where their training opportunities arrive at an exogenous rate.

\subsection{Workers}

The present discounted value of the unemployed skilled worker of origin $J=N, I$ is modified to

$$
\rho U_{h}^{J}=f_{h}^{J}\left(W_{h}^{J}-U_{h}^{J}\right)+\lambda\left(U_{l}^{J}-U_{h}^{J}\right), J=N, I,
$$

where $\lambda$ is the rate by which the high-skilled unemployed worker loses skills and becomes a low-skilled unemployed worker with the value $U_{l}^{J}$ :

$$
\rho U_{l}^{J}=f_{l}^{J}\left(W_{l}^{J}-U_{l}^{J}\right)+\gamma\left(U_{h}^{J}-U_{l}^{J}\right), J=N, I,
$$

where $\gamma$ is the rate by which low-skilled workers regain their skills. This value is assumed to be exogenous, an assumption which is modified in the next section.

The present discounted value for employed workers is still given by equation (2).

\section{$3.2 \quad$ Firms}

The present discounted value of posting a vacancy in sector $s$ is given by equation (3). The value of a job occupied by a worker of origin $J, X_{s}^{J}$, satisfies equation (4) and labour market tightness, $\theta_{s}, s=h, l$, is determined by equation (5).

\subsection{Wage Determination}

As before, wages are determined by Nash Bargaining with equal bargaining power for worker and firm.

Using equations (2)-(4), (9) and (10) gives the equilibrium wages with loss of skill and exogenous training for high-skilled workers and low-skilled workers

$$
\begin{aligned}
& w_{h}^{J}=\frac{\lambda f_{l}^{J} y_{l}+y_{h}\left(2\left((\rho+\sigma) \mu+f_{h}^{J}(\rho+\gamma)\right)+f_{l}^{J}\left(\lambda+\rho+\frac{\rho}{\rho+\sigma} f_{h}^{J}\right)\right)}{D^{J}}, \\
& w_{l}^{J}=\frac{\gamma f_{h}^{J} y_{h}+y_{l}\left(2 \mu(\rho+\sigma)+f_{h}^{J}(\rho+\gamma)+f_{l}^{J}\left(2(\rho+\lambda)+\frac{\rho}{\rho+\sigma} f_{h}^{J}\right)\right)}{D^{J}},
\end{aligned}
$$

where $\mu=(\rho+\lambda+\gamma)$ and $D^{J}=2\left(2(\rho+\sigma) \mu+f_{h}^{J}(\rho+\gamma)\right)+f_{l}^{J}\left(2(\lambda+\rho)+\frac{\rho}{\rho+\sigma} f_{h}^{J}\right)$. As before, high-skilled workers receive higher wages than low-skilled workers if $f_{h}>f_{l}$. Wages in one sector are dependent on labour market conditions in the other sector due to the risk of losing skills and the probability of regaining skills. The transition rate of both sectors will affect wages in both sectors. Hence, when considering discrimination, wages in one sector are directly affected by discrimination in this sector and indirectly affected by discrimination in the other sector. High-skilled natives have higher wages than high-skilled immigrants as they have a higher transition rate from unemployment into employment and therefore a better wage bargaining position. 


\subsection{Unemployment}

The flow equilibrium equations determining the unemployment rates now include the flows between low-skilled and high-skilled unemployment. ${ }^{9}$ This gives the unemployment and employment numbers, where $J=N, I, n^{N}=n$ and $n^{I}=1-n$ :

$$
\begin{aligned}
& \nu_{h}^{J}=\frac{\sigma n^{J}}{\left(\sigma+f_{h}^{J}+\left(f_{l}^{J}+\sigma\right) \frac{\lambda}{\gamma}\right)}, \nu_{l}^{J}=\frac{\lambda}{\gamma} \frac{\sigma n^{J}}{\left(\sigma+f_{h}^{J}+\left(f_{l}^{J}+\sigma\right) \frac{\lambda}{\gamma}\right)} \\
& e_{h}^{J}=\frac{f_{h}^{J} n^{J}}{\left(\sigma+f_{h}^{J}+\left(f_{l}^{J}+\sigma\right) \frac{\lambda}{\gamma}\right)}, e_{l}^{J}=\frac{\lambda}{\gamma} \frac{f_{l}^{J} n^{J}}{\left(\sigma+f_{h}^{J}+\left(f_{l}^{J}+\sigma\right) \frac{\lambda}{\gamma}\right)} .
\end{aligned}
$$

We note the following. In the first case, when $d_{h}=0$ and $d_{l}>0$, we find that employment of high-skilled immigrants is higher than employment of high-skilled natives, $e_{h}^{I} /(1-n)>e_{h}^{N} / n$, whereas employment of lowskilled natives is higher than employment of low-skilled immigrants, $e_{l}^{N} / n>e_{l}^{I} /(1-n)$. This is the case as the transition rate is identical for high-skilled natives and immigrants but lower for low-skilled immigrants than low-skilled natives. This implies that a larger fraction of the high-skilled immigrants will be employed compared to high-skilled natives, and similarly that a greater fraction of low-skilled natives will be employed compared to low-skilled immigrants.

In the second case, both employment fractions relative to the total number of natives and immigrants, respectively, are higher for natives than for immigrants: $e_{s}^{N} / n>e_{s}^{I} /(1-n), s=h, l$. The intuition is here that equal discrimination for both high- and low-skilled immigrants reduces employment of both groups relative to the natives.

The unemployment rates, that is, the number of unemployed as a fraction of the labour force for each skill level, are then again represented by equation (7): $u_{s}^{J}=\frac{\nu_{s}^{J}}{\nu_{s}^{J}+e_{s}^{J}}=\frac{\sigma}{f_{s}^{J}+\sigma}, s=h, l, J=N, I$. However, as $\gamma \nu_{l}^{J}=\lambda \nu_{h}^{J}, J=$ $N, I$ we obtain that the proportion of natives among each skill group for the two different cases are identical.

$$
\phi_{h}=\frac{\nu_{h}^{N}}{\nu_{h}^{N}+\nu_{h}^{I}}=\frac{1}{1+\nu_{h}^{I} / \nu_{h}^{N}}=\frac{1}{1+\frac{(1-n)}{n} \frac{\left(\sigma+f_{h}^{I}+\left(f_{l}^{I}+\sigma\right) \frac{\lambda}{\gamma}\right)}{\left(\sigma+f_{h}^{N}+\left(f_{l}^{N}+\sigma\right) \frac{\lambda}{\gamma}\right)}}
$$

and

$$
\phi_{l}=\frac{1}{1+\left(\nu_{l}^{I} / \nu_{l}^{N}\right)}=\frac{1}{1+\frac{(1-n)}{n} \frac{\frac{\lambda}{\gamma}\left(\sigma+f_{h}^{I}+\left(f_{l}^{I}+\sigma\right) \frac{\lambda}{\gamma}\right)}{\frac{\lambda}{\gamma}\left(\sigma+f_{h}^{N}+\left(f_{l}^{N}+\sigma\right) \frac{\lambda}{\gamma}\right)}}=\phi_{h}=\phi .
$$

In a steady state, the flows between high- and low-skilled workers are identical and the fraction of natives in the unemployment pool is the same for high- and low-skilled workers.

\subsection{Labour Market Tightness}

Labour market tightness for the skilled sector and low-skilled sector is still determined by equation (5). We

\footnotetext{
${ }^{9}$ We have for $J=N, I$, and $n^{N}=n$ and $n^{I}=1-n$ :

$$
\begin{gathered}
\sigma e_{s}^{J} n^{J}=f_{s}^{J} \nu_{s}^{J} n, s=h, l, \sigma e_{h}^{J} n^{J}+\gamma \nu_{l}^{J} n^{J}=f_{h}^{J} \nu_{h}^{J} n^{J}+\lambda \nu_{h}^{J} n^{J}, \\
\sigma e_{l}^{J} n^{J}+\lambda \nu_{l}^{J} n^{J}=f_{l}^{J} \nu_{l}^{J} n^{J}+\gamma \nu_{l}^{J} n^{J},
\end{gathered}
$$

and $u_{h}^{N}+e_{h}^{N}+\nu_{l}^{N}+\nu_{l}^{N}=n, \nu_{h}^{I}+\nu_{h}^{I}+e_{l}^{I}+\nu_{l}^{I}=1-n$. Hence we need that $\gamma \nu_{l}^{J}=\lambda \nu_{h}^{J}, J=N, I$ and using the formulas above we obtain:

$$
\nu_{h}^{J}+\frac{f_{h}^{J}}{\sigma} \nu_{h}^{J}+\frac{f_{l}^{J}}{\sigma} \frac{\lambda}{\gamma} \nu_{h}^{J}+\frac{\lambda}{\gamma} \nu_{h}^{J}=n^{J}
$$
}


substitute for wages from equations (11) and (12) to obtain

$$
\begin{aligned}
\frac{k \theta_{h}^{1-\alpha}}{\mu} & =\sum_{J=N, I} \phi_{h}^{J} \frac{y_{h}\left(2 \mu(\rho+\sigma)+f_{l}^{J}(\rho+\lambda)\right)-\lambda f_{l}^{J} y_{l}}{D^{J}}, \\
\frac{k \theta_{l}^{1-\alpha}}{\mu} & =\sum_{J=N, I} \phi_{l}^{J} \frac{y_{l}\left(2 \mu(\rho+\sigma)+f_{h}^{J}(\rho+\gamma)\right)-\gamma f_{h}^{J} y_{h}}{D^{N}},
\end{aligned}
$$

where $\phi_{s}^{N}=\phi$ and $\phi_{s}^{I}=(1-\phi)\left(1-d_{s}\right), s=h, l$. Loss of skill during a period of unemployment and exogenous retraining implies that labour market tightness in each sector is dependent on labour market conditions in both sectors through the impact on workers' bargaining position and thereby wages. As above, $\theta_{h}>\theta_{l}$, resulting in $f_{h}>f_{l}$ and $w_{h}^{J}>w_{l}^{J}, J=N, I$.

\subsection{Loss of Skill, Exogenous Training, Higher Discrimination and More Immigrants}

When unemployed workers are subject to loss of skills during their unemployment experience, the results on the impact of discrimination change, as the two sectors are now interrelated. Discrimination against immigrants still implies that it takes longer for firms to fill vacancies, which reduces the expected profits from opening vacancies. This in turn reduces vacancy creation and also, in the same way as in the simple model, reduces the fraction of natives among the unemployed. In addition, we now have a new channel as a result of skill loss. Compared to the simple model, loss of skills and retraining link the two sectors and imply that discrimination in one sector affects all native and immigrant workers (not only those who search in that sector). Retraining and loss of skills affect the outside option of all workers irrespective of their current skill type.

\subsubsection{Discrimination in the Low-skilled Sector}

As all workers risk losing skills during unemployment, discrimination against low-skilled workers will affect both low-skilled and high-skilled workers.

Proposition: When discrimination is only present in the low-skilled sector, $d_{h}=0, d_{l}>0$, an increase in discrimination reduces labour market tightness and wages in the low-skilled sector, $d \theta_{l} / d d_{l}<0, d w_{l}^{J} / d d_{l}<0 J=$ $N, I$, and also reduces wages and increases labour market tightness in the high-skilled sector, dw $w_{h}^{J} / d d_{l}<0, J=N, I$, $d \theta_{h} / d d_{l}>0$. Consequently, the low-skilled workers' unemployment rate increases, $d u_{l} / d d_{l}>0$ and high-skilled workers' unemployment rate falls, $d u_{h} / d d_{l}<0$.

Proof: We assume discrimination is present in the low-skilled sector, $d_{h}=0, d_{l}>0$, and differentiate the labour market tightness conditions, (15) and (16) with respect to $\theta_{h}, \theta_{l}$ and $d_{l}$ and obtain $d \theta_{l} / d d_{l}<0$ and $d \theta_{h} / d d_{l}<0$. Next, we differentiate equations (11) and (12) with respect to $d_{l}$ to obtain $d w_{s}^{J} / d d_{l}<0, s=h, l$. Hence, $\theta_{l}$ and $w_{s} s=h, l$ fall and $\theta_{h}$ increases. Differentiating equation (7) with respect to $d_{l}$ using the above results then gives $d u_{l} / d d_{l}>0$ and $d u_{h} / d d_{l}<0$.

Low-skilled immigrants suffer from both direct and indirect effects of discrimination, while low-skilled natives are only negatively affected by the indirect effects. Hence, all low-skilled workers, both natives and immigrants, face lower wages and higher unemployment. The fall in low-skilled workers' wages and transition rates decreases the value of the outside option for all skilled workers, due to the risk of losing skills. Skilled workers' bargaining position is then weakened and they accept lower wages. This makes high-skilled workers more attractive and therefore, more vacancies are opened in this sector, reducing unemployment. Wages rise as there are more vacancies around, but this impact is smaller than the impact of the original wage reduction. Hence, the existence of discrimination in 
the low-skilled sector provides a positive employment externality on the high-skilled sector; it actually increases vacancy supply in the high-skilled sector and thereby employment of all high-skilled native and immigrant workers.

\subsubsection{Discrimination of all High-skilled and Low-skilled Workers}

When all immigrants may experience discrimination, both low and high-skilled workers, the result is more ambiguous.

Proposition: When discrimination is present in both sectors, $d_{h}=d_{l}=d>0$, an increase in discrimination reduces labour market tightness in the high-skilled sector, $d \theta_{h} / d d<0, d w_{h}^{J} / d d<0 J=N, I$, whereas the impact on labour market tightness is ambiguous for the low-skilled sector and the impact on all wages is most likely to be negative. Consequently, the impact on high-skilled workers' unemployment rate is positive whereas the impact on low-skilled workers unemployment rate is ambiguous.

Discrimination in the high-skilled sector directly reduces the return to vacancy supply and as high-skilled workers' bargaining position is negatively affected, they accept lower wages. This is also the case for low-skilled workers due to discrimination in the low-skilled sector. The direct impact on labour market tightness therefore tends to raise unemployment. However, reduced employment prospects in one sector affect the other sector due to skill loss and the probability of regaining skills. As labour market tightness, and therefore the worker's transition rate, is higher in the high-skilled sector than in the low-skilled sector, the direct impact of higher discrimination is larger in the high-skilled sector than in the low-skilled sector. Therefore, wage moderation among low-skilled workers may enhance the profitability of supplying a vacancy in the low-skilled sector to such an extent that labour market tightness increases in this sector and therefore, also the low-skilled worker's transition rate. As labour market tightness for high-skilled workers unambiguously falls, their unemployment rate increases, whereas the impact on the unemployment rate for low skilled workers is ambiguous.

Hence, again we notice that due to loss of skill and the possibility of losing and regaining skills, discrimination in one sector is important for the other sector. In this case, where discrimination is present in both sectors, low-skilled workers, both natives and immigrants, may gain in terms of better employment chances.

\subsubsection{More Immigrants}

In this section we determine the impact of a higher fraction of immigrants. As firm's vacancy supply is affected by the fraction of natives among the job searchers, labour market tightness will be affected.

Proposition: When discrimination is present either in the low-skilled sector, $d_{h}=0, d_{l}>0$, or in both sectors, $d_{h}=d_{l}=d>0$, more immigration, a higher $(1-n)$, reduces labour market tightness and wages in both sectors, $d \theta_{s} / d(1-n)<0, d w_{s}^{J} / d(1-n)<0, J=N, I$, Consequently, both unemployment rates increase, $d u_{s} / d(1-n)>$ 0 . The unemployment rates of natives increase more than that of immigrants.

Proof: We assume discrimination is present in the low-skilled sector, $d_{h}=0, d_{l}>0$, or in both sectors, $d_{h}=$ $d_{l}=d>0$, and differentiate the labour market tightness conditions, (15) and (16) with respect to $\theta_{h}, \theta_{l}$ and $1-n$ and obtain $d \theta_{s} / d(1-n)<0, s=h, l$. Considering equations (11) and (12) we obtain that $d w_{s}^{J} / d(1-n)<0, s=h, l$ and from equation (7) we obtain $d u_{s}^{J} / d(1-n)>0, s=h, l$.

When there is an increase in the share of immigrants, a firm is more likely to match with an immigrant. This increases the expected duration of a vacancy, as discrimination implies that more immigrants are associated with a lower matching frequency. The profitability of opening a vacancy falls. All workers' wages fall as their bargaining position is weakened. This reduction in wages increases the transition rates for workers, modifying the wage reduction. Fewer vacancies increase unemployment of all workers. As native workers' transition rate is higher 
than immigrants' transition rate, the impact is stronger for natives than for immigrants. Therefore natives suffer a higher increase in unemployment, whereby the relative unemployment rate for immigrant relative to native workers decreases.

\section{LOSS OF SKILL AND ENDOGENOUS TRAINING}

In this section we change the assumption of exogenous training to endogenous training. Hence, in this section the workers who have lost skills decide whether they want to retrain or remain as low-skilled workers as opposed to exposure to an exogenous probability of regaining skills.

\subsection{Workers}

The present discounted value of the unemployed skilled worker of origin $J=N, I$ and of employed high- and low-skilled employment are still given by equations (9) and (6) whereas the present discounted value of a low-skilled worker of origin $J=N, I$ is modified to

$$
\rho U_{l}^{J}=f_{l}^{J}\left(W_{l}^{J}-U_{l}^{J}\right), J=N, I .
$$

A low-skilled unemployed worker can choose to search for a job in the low-skilled sector or engage in training. To become high-skilled unemployed, a worker pays a per period cost $c \in U[0 ; 1]$ which is specific to that training opportunity. The effort needed by a worker to retrain in a particular training opportunity depends on the location and time where this training is provided, whether she is healthy or sick, the family situation at that moment, etc. These factors vary over time. Therefore, the fact that a worker chooses to train in one opportunity does not imply that the worker will also train next time he or she loses skills.

The worker compares the present discounted value of training, $U_{t}^{J}(c)$, to the value of being an unemployed high-skilled worker. The value of training is given by

$$
\rho U_{t}^{J}=\gamma^{\prime}\left(U_{h}^{J}-U_{l}^{J}\right)-c^{J}, J=N, I,
$$

where $\gamma^{\prime}$ is the exogenous rate by which the training programme ceases. When this happens, the worker returns to the labour force as a skilled worker. The marginal worker, with cost $\hat{c}^{J}, J=N, I$ is indifferent between training and remaining low-skilled. The marginal worker thus satisfies the condition

$$
\rho U_{l}^{J}=\rho U_{t}^{J}\left(\widehat{c}^{J}\right), J=N, I
$$

Workers with costs of training $c \leq \widehat{c}^{J}, J=N, I$ train, whereas workers with higher costs do not.

\section{$4.2 \quad$ Firms}

The present discounted value of posting a vacancy in sector $s$ is given by equation (3), the value of a job occupied by a worker of origin $J, X_{s}^{J}$ satisfies equation (4) and labour market tightness, $\theta_{s}, s=h, l$, is determined by equation (5).

\subsection{Wages}

Wages are determined by Nash Bargaining and with bargaining power equal to one half. Using equations (9), (6) as well as equation (2)-(4) we obtain: 


$$
\begin{gathered}
w_{h}^{J}=\frac{y_{h}\left((\rho+\lambda)+f_{h}^{J} \frac{\rho}{\rho+\sigma}\right)+y_{l} \frac{\lambda f_{l}^{J}}{2(\rho+\sigma)+f_{l}^{J}}}{2(\rho+\lambda)+f_{h}^{J} \frac{\rho}{\rho+\sigma}}, J=N, I, \\
w_{l}^{J}=y_{l} \frac{\rho+\sigma+f_{l}^{J}}{2(\rho+\sigma)+f_{l}^{J}}, J=N, I .
\end{gathered}
$$

High-skilled workers receive higher wages than low-skilled workers, $w_{h}^{J}>w_{l}^{J}, J=N, I$, if $f_{h}>f_{l}$. As was the case with exogenous training, high-skilled sector wages are affected by conditions in the low-skilled sector due to the risk of losing skills. However, low-skilled wages are no longer affected by conditions in the high-skilled sector as the decision to train is determined by a random cost of effort. High-skilled immigrant wages are then directly affected by discrimination in both the low- and the high-skilled sector whereas low-skilled immigrant wages are only affected by discrimination in the low-skilled sector. As in the two previous versions of the model, natives receive higher wages than immigrants as natives experience a higher transition rate into employment than immigrants.

\subsection{Labour Market Tightness}

Replacing for wages in the equation for labour market tightness in equation (5) to obtain the equations for labour market tightness with loss of skill and endogenous training for the two sectors gives:

$$
\begin{gathered}
k \theta_{h}^{1-\alpha}(\rho+\sigma)-\phi_{h} \Omega_{h}^{N}-\left(1-\phi_{h}\right)\left(1-d_{h}\right) \Omega_{h}^{I}=0, \\
\left.k \theta_{l}^{1-\alpha}-y_{l} \frac{\phi_{l}}{2(\rho+\sigma)+f_{l}}-y_{l} \frac{\left(1-\phi_{l}\right)\left(1-d_{l}\right)}{2(\rho+\sigma)+f_{l}\left(1-d_{l}\right)}\right)=0,
\end{gathered}
$$

where $\Omega_{h}^{J}=\frac{y_{h}(\rho+\lambda)-\frac{y_{l} \lambda f_{l}^{J}}{2(\rho+\sigma)+f_{l}^{J}}}{2(\rho+\lambda)+f_{h}^{J} \frac{\rho}{\rho+\sigma}}, J=N, I$. In order to determine the relative size of labour market tightness in the high and low productivity sector, we need to determine the relative size of $\phi_{h}$ and $\phi_{l}$, which in turn depends on the relative size of $f_{h}$ and $f_{l}$.

In the section on unemployment and skills below, we show that $\phi_{h}<\phi_{l}$ in case 1 where $d_{h}=0$ and $d_{l}>0$. In this case, labour market tightness for high-skilled workers is higher than labour market tightness for low-skilled workers for the following reason: high-skilled workers have higher productivity and there are relative more immigrants in the unemployment pool for high-skilled workers than for low-skilled workers, and immigrants receive lower wages than natives and are therefore relatively more profitable (there is no direct negative impact on labour market tightness in the high-skilled sector from discrimination).

In case 2, we cannot determine the relative size of $\phi_{h}$ and $\phi_{l}$. Therefore the relative size of labour market tightness is ambiguous.

\subsection{Training}

We insert equation (17) into the training equation (18), substitute for values and then wages, to obtain the equation determining the marginal worker who trains:

$$
\hat{c}^{J}=\frac{\gamma^{\prime} f_{h}^{J} y_{h}-\frac{y_{l} f_{l}^{J}}{2(\rho+\sigma)+f_{l}}\left(\frac{\rho+\gamma^{\prime}}{\rho+\sigma} f_{h}^{J}+2\left(\rho+\lambda+\gamma^{\prime}\right)\right)}{2(\rho+\lambda)+f_{h}^{J} \frac{\rho}{\rho+\sigma}}, J=N, I .
$$

A necessary condition for workers to train is that the right hand side is positive. For this to be the case, the probability of obtaining a high-skilled job needs to be high, $f_{h}^{J}$ high, and so does the difference in productivity 
achieved by training, $y_{h}-y_{l}$. We also note that the right hand side of equation (23) is less than one, which ensures that $\hat{c}^{J}<1$.

Proposition: When discrimination is present only in the low-skilled sector, $d_{h}=0, d_{l}>0$, more immigrants than natives acquire training, $\hat{c}^{I}>\hat{c}^{N}$. When discrimination is present in both sectors, $d_{h}=d_{l}=d>0$, the relative number of immigrants and natives acquiring training is ambiguous.

When only low-skilled workers are discriminated against, low-skilled immigrants are worse relative to low-skilled natives, whereas high-skilled immigrants and natives consider the same labour market tightness. Consequently, it is more attractive to acquire training for immigrants than for natives. When discrimination is present for both low-skilled and high-skilled workers, the relative training decision is ambiguous. Discrimination against high-skilled workers tends directly to raise the number of high-skilled natives relative to high-skilled immigrants, but, on the other hand, discrimination against low-skilled workers tends to raise the number of training immigrants. On the whole, it cannot be determined whether there are more or less natives than immigrants who train in the case of equal discrimination in the two sectors.

\subsection{Unemployment and Skills}

The flow equilibrium equations determining the unemployment rates now include the flows between low-skilled and high-skilled unemployment, where the flow from the low-skilled to high-skilled labour force is endogenous. The flow into low-skilled unemployment from high-skilled unemployment is equal to the flow from low-skilled unemployment into high-skilled unemployment. ${ }^{10}$

As unemployment rates are the number of unemployed relative to the number of workers in the labour force for each skill level, we obtain the same unemployment rates as in the previous two versions of the model, equation (7).

The proportions of natives among the unemployed workers of high-skill level and low-skilled level become:

$$
\phi_{h}=\frac{1}{1+\frac{1-n}{n} \kappa}, \phi_{l}=\frac{1}{1+\frac{\hat{c}^{N}}{\hat{c}^{I}} \frac{1-n}{n} \kappa},
$$

where $\kappa=\frac{\sigma+f_{h}^{N}+\left(f_{l}^{N}+\sigma\right) \frac{\lambda}{\hat{c}^{N}}+\frac{\sigma \lambda}{\gamma^{\prime}}}{\sigma+f_{h}^{I}+\left(f_{l}^{I}+\sigma\right) \frac{\lambda}{\hat{c}^{I}}+\frac{\sigma \lambda}{\gamma^{\prime}}}$. We note that the proportion of natives among the high-skilled unemployed workers will be greater than the proportion of natives among the low-skilled unemployed workers if natives choose to train more than immigrants, that is $\phi_{h} \gtreqless \phi_{l}$ if $\hat{c}^{N} \gtreqless \hat{c}^{I}$. This is the case as more natives training directly increases the labour force of high-skilled natives relative to high skilled immigrants and at the same time increases the number of low-skilled immigrants relative to high-skilled immigrants.

Concerning the impact of relative training on both proportions of natives among the unemployment, that is on both $\phi_{h}$ and $\phi_{l}$, we find that more natives acquiring skills relative to immigrants, that is a higher $\hat{c}^{N} / \hat{c}^{I}$, has two impacts. A higher $\hat{c}^{N} / \hat{c}^{I}$ increases unemployment of high-skilled natives relative to unemployment of high-skilled immigrants, reducing $\kappa$ and thereby increases $\phi_{h}$. A higher $\hat{c}^{N} / \hat{c}^{I}$ also directly reduces the fraction of natives among the low-skilled workers. The latter impact is the stronger and therefore the impact of higher $\hat{c}^{N} / \hat{c}^{I}$ on $\phi_{l}$ is negative.

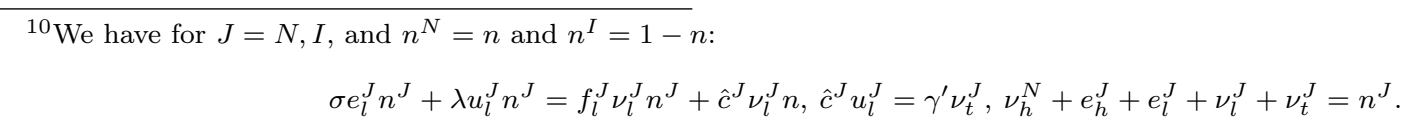

We need $\gamma^{\prime} \nu_{t}^{J}=\lambda \nu_{h}^{J}=\hat{c}^{J} \nu_{l}^{J}$ and obtain the following unemployment and employment equations

$$
\begin{gathered}
\nu_{h}^{J}=\frac{\sigma n^{J}}{\sigma+f_{h}^{N}+\left(f_{l}^{N}+\sigma\right) \frac{\lambda}{\hat{c}^{N}}+\frac{\sigma \lambda}{\gamma^{\prime}}}, \nu_{l}^{J}=\frac{\lambda}{\hat{c}^{N}} \frac{\sigma n^{J}}{\sigma+f_{h}^{N}+\left(f_{l}^{N}+\sigma\right) \frac{\lambda}{\hat{c}^{J}}+\frac{\sigma \lambda}{\gamma^{\prime}}}, \\
e_{h}^{J}=\frac{f_{h}^{J} n^{J}}{\sigma+f_{h}^{J}+\left(f_{l}^{J}+\sigma\right) \frac{\lambda}{\hat{c}^{J}}+\frac{\sigma \lambda}{\gamma^{\prime}}}, e_{l}^{J}=\frac{\lambda}{\hat{c}^{J}} \frac{f_{l}^{J} n^{J}}{\sigma+f_{h}^{J}+\left(f_{l}^{J}+\sigma\right) \frac{\lambda}{\hat{c}^{J}}+\frac{\sigma \lambda}{\gamma^{\prime}}} .
\end{gathered}
$$


In case 1, where discrimination is present in the low-skilled sector only, $d_{h}=0$ and $d_{l}>0$, the proportion of natives among the unemployed workers is higher for low-skilled workers than high-skilled workers as $\hat{c}^{N}<\hat{c}^{I}$. That is, more immigrants than natives train and therefore there are more natives in the low-skilled unemployment pool than in the high-skilled one, $\phi_{h}<\phi_{l}$. In the second case, where all immigrants are discriminated against, $d_{h}=d_{l}=d>0$, relative training of natives and immigrants is ambiguous and therefore the relative size of $\phi_{h}$ and $\phi_{l}$ is ambiguous.

Finally, we consider the proportion of skilled workers in the economy. This fraction will depend on where there is discrimination:

$$
\frac{\nu_{h}^{J}+e_{h}^{J}}{n^{J}}=\frac{\sigma+f_{h}^{J}}{\sigma+f_{h}^{J}+\left(f_{l}^{J}+\sigma\right) \frac{\lambda}{\hat{c}^{j}}+\frac{\sigma \lambda}{\gamma^{\prime}}}, J=N, I
$$

In the first case, where discrimination is present in the low-skilled sector only, $d_{h}=0$ and $d_{l}>0$, the proportion of high-skilled workers is higher among immigrants than natives, as low-skilled immigrants have a stronger incentive to train than low-skilled natives. In the second case, when there is discrimination in both sectors, $d_{h}=d_{l}=d>0$, we cannot immediately determine whether the proportion of skilled workers is higher among natives than among immigrants.

\subsection{Loss of Skill, Endogenous Training, Higher Discrimination and More Immigrants}

In this section we examine the impact of discrimination and immigration on labour market performance given training is endogenous. Discrimination against immigrants still implies that it takes longer for firms to fill vacancies, which reduces vacancy supply, but the impact of discrimination in one sector on the other sector is now modified. The endogenous skill choice decision implies that how discrimination affects immigrants' and natives' incentives to regain skills will be important.

\subsubsection{Discrimination in the Low-skilled Sector}

When discrimination is present in the low productivity sector, $d_{h}=0, d_{l}>0$, native wages will be higher than immigrant wages for both high and low productivity workers, $w_{s}^{N}>w_{s}^{I}, s=h, l$. High-skilled native workers have higher wages than immigrants, even though there is no discrimination in the high-skilled sector, as the risk of losing skills reduces the skilled worker's bargaining power when discrimination exists for low-skilled workers. We therefore have the following result.

Proposition: When training is endogenous and discrimination exists in the low-skilled sector, $d_{h}=0, d_{l}>$ 0 , an increase in discrimination induces more low-skilled unemployed immigrant workers to train, d $\widehat{c}^{I} / d d_{l}>0$, reduces labour market tightness and wages in the low-skilled sector, $d \theta_{l} / d d_{l}<0, d w_{l}^{J} / d d_{l}<0 J=N, I$, and reduces wages and increases labour market tightness in the high-skilled sector, $d w_{h}^{J} / d d_{l}<0, J=N, I, d \theta_{h} / d d_{l}>$ 0. Consequently, the low-skilled workers' unemployment rate increases, $d u_{l} / d d_{l}>0$ and high-skilled workers' unemployment rate falls, $d u_{h} / d d_{l}<0$. Natives also train more but the impact is smaller than the impact on immigrants, $d \widehat{c}^{N} / d d_{l}>0, d \widehat{c}^{I} / d d_{l}>d \widehat{c}^{N} / d d_{l}$. The proportion of high-skilled workers among the immigrants increases relative to the proportion of high-skilled workers among the natives.

Proof: We assume $d_{h}=0, d_{l}>0$, and differentiate the labour market tightness equations, (15) and (16) with respect to $\theta_{h}, \theta_{l}$ and $d_{l}$ and consider the impact around $d_{l}=0$ to obtain $d \theta_{l} / d d_{l}<0$ and $d \theta_{h} / d d_{l}>0$ implying $d u_{l} / d d_{l}>0$ and $d u_{h} / d d_{l}<0$. Differentiating the wage equation for low-skilled workers, (20) with respect to $d_{l}$ gives $d w_{l} / d d_{l}<0$ and as the high-skilled sector is not directly affected around $d_{l}=0$ by $d_{l}$ but only through wages, high skilled wages must fall. Differentiating equation (23) with respect to $d_{l}$ gives $d \widehat{c}^{J} / d d_{l}>0, J=N, I$. As low-skilled 
immigrants are more negatively affected than natives, due to the direct impact from discrimination, and natives are only affected through reduced labour market tightness in the low skilled sector, we obtain that $d \widehat{c}^{I} / d d_{l}>d \widehat{c}^{N} / d d_{l}$ and hence $d \frac{\nu_{h}^{I}+e_{h}^{I}}{n^{I}} / d d_{l}>d \frac{\nu_{h}^{N}+e_{h}^{N}}{n^{N}} / d d_{l}$.

Low-skilled immigrants are affected both directly and indirectly by discrimination, while low-skilled natives are only negatively affected by the indirect effect. Hence, all low-skilled workers face lower wages and higher unemployment. The fall in low-skilled workers' wages and transition rates lowers the value of the outside option for all high-skilled workers, due to the risk of losing skills. High-skilled workers' bargaining position then worsens, implying they accept lower wages. High-skilled workers are now more attractive, which increases vacancy supply in this sector, thus reducing unemployment. Discrimination in the low-skilled sector reduces wages in the highskilled sector, as the positive impact due to more vacancies is smaller than the original wage reduction. Hence, as with exogenous training, the existence of discrimination in the low-skilled sector provides a positive employment externality on the high-skilled sector; vacancy supply and thus employment increase in the high-skilled sector.

Both the diminished employment prospects for low-skilled workers and the higher transition rate for high-skilled workers induce low-skilled immigrants and natives to train more. Training therefore increases. As immigrants are both directly and indirectly affected by discrimination whereas natives are only indirectly affected, immigrants have greater incentives to acquire skills. Thus, the positive impact on training is larger for immigrants than for natives. This further increases the proportion of high-skilled among the immigrants, which is greater than the increase in the proportion of high-skilled among the natives.

Hence, notice here that discrimination against low-skilled workers has a positive impact on the distribution of skills for immigrants relative to natives. While discrimination does imply that low-skilled immigrants suffer more than low-skilled native workers, in terms of lower employment chances and lower wages, they at the same time have larger incentives to acquire training. For those with sufficiently low training costs, they train to a larger extent than natives and, by doing so, escape the discrimination influenced low-skilled sector.

\subsubsection{Discrimination of all High-skilled and Low-skilled Workers}

When all immigrants may experience discrimination, both low and high-skilled workers, the result is, as above with exogenous training, more ambiguous.

Proposition: When training is endogenous and discrimination is present in both sectors, $d_{h}=d_{l}=d>0$, an equal increase in discrimination has an ambiguous impact on training, reduces labour market tightness in the low-skilled sector and all wages, $d \theta_{l} / d d<0, d w_{s}^{J} / d d<0 J=N, I, s=h, l$ whereas the impact on labour market tightness is ambiguous for the high-skilled sector. Consequently, the unemployment rate for low-skilled workers increases, $d u_{l}^{J} / d d>0$ whereas $d u_{h}^{J} / d d$ has an ambiguous sign. The impact on the proportion of natives among the high and low-skilled unemployed workers is ambiguous.

Notice here that the low-skilled workers' unemployment rate increases and their wages fall but we cannot determine whether labour market tightness increases or falls in the high-skilled sector. The reason is that despite the fact that discrimination directly tends to reduce labour market tightness in the high-skilled sector, the negative impact on wages has a positive impact on labour market tightness. This also implies that we cannot determine whether the proportion of natives among the high and low-skilled workers increases or falls.

\subsubsection{More Immigrants}

The impact of more immigrants is equivalent to what we obtained when training was exogenous.

Proposition: When discrimination is either present in the low-skilled sector, $d_{h}=0, d_{l}=d>0$, or in both sectors, $d_{h}=d_{l}=d>0$, a higher fraction of immigrants, $(1-n)$, reduces labour market tightness and wages in 
both sectors, $d \theta_{s} / d(1-n)<0, d w_{s}^{J} / d(1-n)<0 J=N, I$, and reduces training for both natives and immigrants, $d \hat{c}^{J} / d(1-n)<0, J=N, I$. Consequently, both unemployment rates increase, $d u_{s} / d(1-n)>0$. The unemployment rates of natives increase more than immigrants' unemployment rates reducing inequality in terms of unemployment rates, $d u_{s}^{N} / d n>d u_{s}^{I} / d n, s=h, l$.

Proof: We assume discrimination is present in only the low-skilled sector or both sectors, $d_{h}=0, d_{l}>0$ or $d_{h}=d_{l}=d>0$, and differentiate equations (15) and (16) with respect to $\theta_{h}, \theta_{l}$ and $1-n$ taking the impact on training and thereby $\phi_{s}$ into account, and obtain a negative impact on labour market tightness in both sectors. Differentiating equation (23) with respect to $\theta_{h}$ gives a positive sign and with respect to $\theta_{l}$ gives a negative sign. The negative impact on $\theta_{h}$ is stronger than the negative impact on $\theta_{l}$ and training therefore falls. Differentiating the wage equation for high skilled and low-skilled workers, (19) and (20), with respect to $1-n$ gives a negative sign.

As was the case with exogenous training, the increase in the share of immigrants, increases the likelihood that a high-productivity firm matches with an immigrant. This increases the expected duration of a vacancy, as discrimination implies that more immigrants are associated with a lower matching frequency. As a result, fewer vacancies are opened. As before, we still have that the reduction in wages increases the transition rates for workers, modifying the wage reduction.

The additional impact of the introduction of endogenous training varies depending on where discrimination exists. In case one, the reduction of labour market tightness for high-skilled workers has a stronger impact on training for natives than immigrants. However, the relative impact of lower labour market tightness for immigrants is ambiguous and therefore, with endogenous training, the impact on the fraction of natives training is also ambiguous. In the low-skilled sector, the impact of both high- and low-skilled labour market tightness on the fraction of natives training is ambiguous and therefore, this impact may either reinforce or diminish the initial impact of additional immigrants on labour market tightness. In case two, this additional impact is also ambiguous, as we cannot even determine whether lower labour market tightness for high skilled workers leads to immigrants training more than natives or the reverse.

When the reduction in training is larger for natives than immigrants, the share of natives among the unemployed high-skilled workers falls and there is a further reduction of labour market tightness in the high-skilled sector. This in turn corresponds to relatively more natives among the low-skilled workers, which will tend to increase labour market tightness and therefore reduce unemployment. As argued above, this is most likely to happen when discrimination is present in the high-skilled sector also, and in this situation, more immigrants may be very little harmful for the low-skilled workers.

Conversely, if the reduction in training is more severe for immigrants than natives, the fraction of natives among the unemployed high-skilled workers will tend to increase, which will modify the negative impact on high-skilled labour market tightness but at the same time reduce the fraction of natives among the low-skilled workers. This will lead to a further reduction in labour market tightness in the low-skilled sector. In this case, the impact on wages and unemployment for high-skilled workers may be negligible, whereas it will be even stronger for low-skilled workers.

\section{$5 \quad$ NET OUTPUT}

In this section, we examine the impact of discrimination on net output when training is exogenous for the two different cases investigated throughout the paper.

We use a utilitarian welfare function, which is obtained by adding all individuals' and firms' steady state flow values of net output in both the high- and the low-skilled sector. To disregard congestion externalities, we assume 
that $\alpha=1 / 2$, that is we impose the traditional Hosios condition (Hosios 1990), where the elasticity of the expected duration of a vacancy is equal to the bargaining power of workers in a symmetric Nash bargaining situation. Using the asset equations for workers and firms in the two sectors, imposing the flow equilibrium conditions and considering the case of no discounting, i.e., $\rho \rightarrow 0,{ }^{11}$ we can write the welfare function as production minus vacancy costs, $W=e_{h} y_{h}+e_{l} y_{l}-v_{h} \theta_{h} k-v_{l} \theta_{l} k$ which is equal to $W=\sum_{s=h, l}\left(\left(e_{s}^{N}+e_{s}^{I}\right) y_{s}-\left(e_{s}^{N}+\frac{e_{s}^{I}}{1-d_{s}}\right) \sigma f_{s} k\right)$. Assuming risk neutral individuals, we ignore distributional issues and hence, wages will not feature in the welfare function.

We consider the impact on welfare resulting from an increase in discrimination for the two cases we have studied throughout the paper plus an additional case, where discrimination may differ for the two different sectors. We then discuss the impact on net output resulting from a higher fraction of immigrants. In case one, we consider the increase in discrimination when $d_{h}=0, d_{l}>0$ around $d_{h}=d_{l}=0$ :

$$
\frac{\partial W}{\partial d_{l}}=\frac{d e_{h}}{d d_{l}} y_{h}+\frac{d e_{l}}{d d_{l}} y_{l}-\sigma \frac{d e_{h}}{d d_{l}} f_{h} k-\sigma\left(\frac{d e_{l}}{d d_{l}}+e_{l}\right) f_{l} k-\frac{\sigma e_{l}}{2 f_{l}} \frac{d \theta_{l}}{d d_{l}}
$$

In case two, with discrimination in both sector, $d_{h}=d_{l}=d>0$, we obtain around $d_{h}=d_{l}=0$ :

$$
\frac{\partial W}{\partial d}=\frac{d e_{h}}{d d} y_{h}+\frac{d e_{l}}{d d} y_{l}-\sigma\left(\frac{d e_{h}}{d d}+e_{h}^{I}\right) f_{h} k-\frac{\sigma e_{h}}{2 f_{h}} \frac{d \theta_{h}}{d d}-\frac{\sigma e_{l}}{2 f_{l}} \frac{d \theta_{l}}{d d}-\sigma\left(\frac{d e_{l}}{d d}+e_{l}\right) f_{l} k .
$$

When there is only discrimination in the low-productivity sector, two divergent effects emerge. Employment falls for low-skilled workers, which tends to reduce net output, and employment increases for high-skilled workers, which increases net output. The impact of reduced hiring costs represented by the last three terms has a smaller impact on net output than the impact through employment.

Equation (25) shows that as discrimination in the high-productivity sector reduces employment in sector $h$, this decreases net output in that sector. However, as the impact on labour market tightness is ambiguous for the low-skilled sector, the impact on low-skilled employment, and thereby net output, is also ambiguous. As above, the impact of reduced hiring costs represented by the last three terms has a smaller impact on net output than the impact through employment.

Substituting for employment changes, wages and labour market tightness equations when $\rho=0$ and around $d_{h}=d_{l}=d=0$ gives:

$$
\begin{gathered}
\frac{\partial W}{\partial d_{l}}=-e_{l}^{N}\left(\frac{-f_{h}\left(y_{h}-\sigma f_{h} k-\left(y_{l}-\sigma f_{l} k\right)\right)+\sigma\left(1+\frac{\lambda}{\gamma}\right)\left(y_{l}-\sigma f_{l} k\right)}{\sigma+f_{h}+\left(f_{l}+\sigma\right) \frac{\lambda}{\gamma}}+\sigma f_{l} k\right) \\
\frac{\partial W}{\partial d}=-\left(1+\frac{\lambda}{\gamma}\right) e_{l}^{I}\left(\frac{\sigma \frac{\gamma}{\lambda} \frac{f_{h}}{f_{l}}\left(y_{h}-\sigma f_{h} k\right)+\sigma\left(y_{l}-\sigma f_{l} k\right)}{\sigma+f_{h}+\left(f_{l}+\sigma\right) \frac{\lambda}{\gamma}}+\sigma f_{l} k\right)<0 .
\end{gathered}
$$

Notice that for $\rho=0$ we obtain $y_{s}-\sigma f_{s} k=w_{s}, s=h, l$ and from equation (4) we have $\left(y_{h}-\sigma f_{h} k\right)>\left(y_{l}-\sigma f_{l} k\right)$. We observe that net output unambiguously falls when discrimination is present in both sectors, but there is a counteracting impact on net output when discrimination only affects the low-skilled workers for the following reason. Higher discrimination for low-skilled workers reduces low-skilled immigrants' transition rate, and thereby employment and net output in the low-skilled sector. On the other hand, reduced employment prospects for lowskilled workers reduce the bargaining power of the high-skilled immigrant workers as, in the case when they lose their skills, they have a lower transition rate. Lower wages in the high-skilled sector therefore improve net output in the high-skilled sector and thus contributes positively to total net output. The impact on net output due to only

\footnotetext{
${ }^{11}$ We ignore discounting in order to compare different steady states without needing to consider the adjustment process. This is common in the literature, see for example, Engström et al (2005).
} 
low-skilled discrimination is ambiguous.

Finally, we consider the impact on net output from higher discrimination for high-skilled workers compared to the impact from discrimination of low-skilled workers. In this third case where $d_{h}>0$ and $d_{l}=0$ we obtain around $d_{h}=d_{l}=0$ :

$$
\frac{\partial W}{\partial d_{h}}=\frac{d e_{h}}{d d_{h}} y_{h}+\frac{d e_{l}}{d d_{h}} y_{l}-\sigma\left(\frac{d e_{h}}{d d_{h}}+e_{h}^{I}\right) f_{h} k--\frac{\sigma e_{l}}{2 f_{h}} \frac{d \theta_{h}}{d d_{h}} k-\frac{\sigma e_{l}}{2 f_{l}} \frac{d \theta_{l}}{d d_{h}} k-\sigma \frac{d e_{l}}{d d_{h}} f_{l} k
$$

Substituting for employment changes, wages and using the labour market tightness equations we obtain:

$$
\frac{\partial W}{\partial d_{h}}=-e_{h}^{I}\left(\frac{\sigma\left(1+\frac{\lambda}{\gamma}\right)\left(y_{h}-\sigma f_{h} k\right)+f_{l} \frac{\lambda}{\gamma}\left(y_{h}-\sigma f_{h} k-\left(y_{l}-\sigma f_{l} k\right)\right)}{\left(\sigma+f_{h}^{N}+\left(f_{l}^{N}+\sigma\right) \frac{\lambda}{\gamma}\right)}+\sigma f_{h} k\right)<0 .
$$

As the reduction in employment and thereby net output in the high productivity sector dominates the increase in employment and net output in the low-skilled sector, discrimination in the high-productivity sector reduces net output in the economy. This results from the downward pressure on low-skilled wages. Comparing the negative impact on net output due to discrimination in the high-skilled sector to the effect resulting from discrimination in the low-skilled sector, we see that the negative impact on net output is strongest if discrimination is present in the high-skilled sector. The reason is that the negative impact on employment, and thus net output, is increasing in productivity. Hence, discrimination in the high-skilled sector is more severe than in the low-skilled sector. We therefore have the following result:

Proposition: The negative impact on net output is more severe when discrimination is present in the high-skilled sector, $d_{h}>0, d_{l}=0$, than when discrimination is present in the low-skilled sector, $d_{h}=0, d_{l}>0$.

Proof: This immediately follows from comparing equation (26) and (28) and noting that $y_{h}-\sigma f_{h} k>y_{l}-\sigma f_{l} k$ and $\sigma f_{h} k>\sigma f_{l} k$.

When the fraction of immigrants increases, we obtain $\frac{d W}{d(1-n)}=-\frac{d W}{d n}$ where

$$
\begin{gathered}
\frac{d W}{d n}=\left(\frac{d e_{h}^{N}}{d n}+\frac{d e_{h}^{I}}{d n}\right) y_{h}-\left(\frac{d e_{h}^{N}}{d n}+\frac{d e_{h}^{I}}{d n} \frac{1}{1-d_{h}}\right) \sigma f_{h} k-\sigma\left(\left(e_{h}^{N}+e_{h}^{I} \frac{1}{1-d_{h}}\right)\right) \frac{1}{2 f_{h}} \frac{d \theta_{h}}{d n} k+ \\
\left(\left(\frac{d e_{l}^{N}}{d n}+\frac{d e_{l}^{I}}{d n}\right) y_{l}-\sigma\left(\frac{d e_{l}^{N}}{d n}+\frac{d e_{l}^{I}}{d n} \frac{1}{1-d_{l}}\right) f_{l} k-\sigma\left(e_{l}^{N}+e_{l}^{I} \frac{1}{1-d_{l}}\right) \frac{1}{2 f_{l}} \frac{d \theta_{l}}{d n} k\right),
\end{gathered}
$$

which after substituting for employment changes, wages and using the labour market tightness equations when $\rho=0$ reduces to

$$
\frac{d W}{d(1-n)}=\left(\frac{e_{h}^{I}}{1-n}-\frac{e_{h}^{N}}{n}\right)\left(y_{h}-\sigma f_{h} k\right)+\left(\frac{e_{l}^{I}}{1-n}-\frac{e_{l}^{N}}{n}\right)\left(y_{l}-\sigma f_{l} k\right) .
$$

Proposition: The impact on net output due to a higher fraction of immigrants, $d W / d(1-n)$ is ambiguous in case 1 and 3 and negative in case 2, where discrimination is equally present in both sectors.

Proof. Notice that $y_{h}-\sigma f_{h} k>y_{l}-\sigma f_{l} k$. In case 1 , when $d_{h}=0$ and $d_{l}>0$, the value of the first parenthesis of equation (29) is positive, whereas the value of the third is negative. Hence, the sign is ambiguous. In case 2, when $d_{h}=d_{l}=d>0$, the values of first parenthesis and the third are negative and hence $d W /(1-n)<0$. Finally, in case 3, when $d_{h}>0, d_{l}=0$, the value of the first parenthesis is negative and the value of the third is positive giving an ambiguous sign. 
The impact of more immigration on net output varies dependent upon in which sector there is discrimination. In case 1, when discrimination is present in the low skilled sector only, high-skilled immigrant employment as a fraction of the number of total immigrants is higher than high-skilled native employment as a fraction of the total number of natives. The reverse holds for low-skilled workers. Therefore, a higher fraction of immigrants in the labour force contributes to more high-skilled production but less low-skilled production, where the latter impact is larger. As the production contribution to net output is higher for high-skilled workers than for low skilled workers, we can therefore not determine the total impact on net output.

In case 2, when discrimination is equally present in both sectors, employment and thereby production, decrease for both skill groups reducing net output. Finally, in case $\mathbf{3}$ when only high-skilled workers experience discrimination, increasing the fraction of immigrants raises the production contribution from low skilled workers, but as high-skilled workers produce less, the total impact on net output is ambiguous.

\section{SIMULATIONS}

The model with exogenous training is illustrated given the following parameter values (annual values). The discount rate is set to $\rho=0.08$, the separation rate is $\sigma=0.1$ (see Millard and Mortensen 1997), $\alpha=0.5$ (Pissarides 1986), $y_{l}$ is normalised to one, and $y_{h}$ is set equal to 1.3 to obtain a relative large difference between productivity levels in the two sectors and thereby differences which are visible in the graphs. We consider Sweden as Sweden is a country where discrimination against immigrants is relatively low. The fraction of natives was around $n=0.88$ in Sweden in 2013 (www.oecd.org). The parameters $\lambda$ and $\gamma$ are set so as to match the fraction of high-skilled unemployed workers relative to long-term unemployed workers for natives and immigrants. From the model we have that these fractions are $\nu_{h}^{N} / \nu_{l}^{N}=\nu_{h}^{I} / \nu_{l}^{I}=\lambda / \gamma$. For Sweden in 2013, we divide workers into two groups, those who have been unemployed for more (the long-term unemployed) or less (the short-term unemployed) than 6 months measured in 1000 persons. We then have that $\nu_{h}^{N} / \nu_{l}^{N}=(266-64.4) / 64.4=3.1$ for natives and $\nu_{h}^{I} / \nu_{l}^{I}=$ $(144.8-56.8) / 56.8=1.5$ (Statistika Centralbyrån, www.scb.se). In the model, these two numbers are supposed to be identical equal to $\lambda / \gamma$ and we therefore pick a number in between but closest to the number for natives, as there are relatively more of them, namely $\lambda=0.27$ and $\gamma=0.108$ giving $\lambda / \gamma=2.5$. We match unemployment rates for Sweden when the discrimination rates are $d_{h}=d_{l}=0.2$ so as to obtain a significant difference between natives and immigrants. The hiring costs are set equal to $k=0.4$ to match an unemployment rate for both high- and low-skilled

native workers for Sweden in 2013, $\frac{\nu^{N}}{n}=\frac{\nu_{h}^{N}+\nu_{l}^{N}}{n}=\frac{\left(1+\frac{\lambda}{\gamma}\right) \sigma}{\left(\sigma+f_{h}+\left(f_{l}+\sigma\right) \frac{\lambda}{\gamma}\right)}=\frac{(1+2.5) 0.1}{(0.1+2+(1.2+0.1) 2.5)}=0.063$, where the total unemployment rate for the natives is found using equation (13) (http://ec.europa.eu/eurostat). A discrimination rate of $d_{h}=d_{l}=0.2$ gives an unemployment rate of immigrants of $\nu^{I} /(1-n)=\left(\nu_{h}^{N}+\nu_{l}^{N}\right) /(1-n)=0.078$. The remaining difference in unemployment for natives and immigrants (0.162 in 2013) is due to factors other than discrimination, that is, factors not represented by this model.

We present six graphs in this section and additional robustness checks in the appendix. In the first three graphs we present the simulations for transition rates, unemployment and wages for the high-skilled and low-skilled sector for natives and immigrants, where we increase discrimination in the low-skilled sector from $d_{l}=0$ to $d_{l}=0.5$ while keeping discrimination in the high-skilled sector $d_{h}=0$. In the next three graphs we again consider the impact on transition rates, unemployment and wages for the high-skilled and low-skilled sector for natives and immigrants where we let $d_{h}=d_{l}=d$ and increase $d$ from 0 to 0.5 .

Regarding Figure 1, the transition rates for high-skilled workers are well above transition rates for low-skilled workers due to different productivities. There is very little movement in the transition rates for native low-skilled workers as $d_{l}$ increases. The transition rate for high-skilled workers increases slightly, consistent with their wage decreases, and the transition rate for low-skilled immigrants falls significantly with $d_{l}$. These results for the transition 
rates imply that the unemployment rate is much higher for low-skilled workers than high-skilled workers, moves very little for natives and high-skilled immigrant workers, but increases a lot for low skilled immigrant workers when $d_{l}$ increases (see Figure 2). Concerning wages, both high-skilled and low-skilled immigrant wages decrease with discrimination in the low-skilled sector, however, the decline is sharper for low-skilled workers as this sector is directly and negatively affected while the former decline is consistent with the increase in the transition rate for high-skilled workers (Figure 3).

When we consider the impact of discrimination in both sectors (Figures 4-6), we obtain a sharp decrease in the transition rates for both high- and low-skilled immigrants, whereas the transition rates for natives are almost unchanged. As the transition rate is greater for high-skilled than low-skilled workers, the former decreases more than the latter. The transition rate facing high-skilled immigrants actually ends up lower than the transition rate for low-skilled natives when discrimination becomes relatively high and therefore unemployment for high-skilled immigrants exceeds the unemployment rate of low-skilled native workers at this discrimination level (Figure 5). As labour market tightness corresponding to the transition rate for natives is relatively unaffected by discrimination, the unemployment increase for low-skilled immigrant workers is similar to the increase for low-skilled immigrants in the first case, where there is only discrimination in the low-skilled sector. In case 2, there is a much sharper decrease in both high- and low-skilled immigrant wages than in case 1, due to the fact that the possibility of skill loss for high-skilled and the probability of regaining skills for low-skilled implies an interaction effect between the two sectors. This will amplify any negative effect on one of the two sectors. High-skilled immigrants' wages now fall more than low-skilled immigrants' wages due to the larger direct negative impact on high-skilled immigrant transition rate and the corresponding larger decrease in their bargaining power.

In the appendix, Section 8.3, we examine how the parameter values affect the results in the two cases, when $d_{h}=0, d_{l}=0.2$ and $d_{h}=d_{l}=d=0.2$ and show the following. In panel 1 , we notice that a higher $\lambda$ will actually reduce unemployment as wages fall, which raises workers' transition rates. When $\gamma$ increases, (panel 2) unemployment increases together with higher wages, resulting in a lower transition rate into employment for all workers, but particularly for low-skilled workers as they are directly affected. In panel 3, we see that a higher separation rate has a huge positive impact on unemployment and a large negative impact on wages as both workers and firms are worse off when the separation rate into unemployment is higher. Panels 4 and 5 show how the results are modified if we allow for different separation rates for the two sectors (the modified equations are given in the Appendix). When $\sigma_{l}=0.1$ and $\sigma_{h}$ increases we see, as expected, that the unemployment rate for high-skilled workers increases, whereas the unemployment rate for low-skilled workers actually falls. This is due to the fact that there is no direct impact on unemployment for the low-skilled workers but wages fall for all workers as workers are worse off when $\sigma_{h}$ increases (for low-skilled workers this is also due the probability of regaining skills). The negative impact for wages will be larger for high-skilled workers than low-skilled workers as there is a direct negative impact on firms in the high-skilled sector but not in the low-skilled sector. Similarly, as is seen in panel 5, when $\sigma_{h}=0.1$ and we let $\sigma_{l}$ increase, then $u_{l}^{J}, J=N, I$ increases whereas $u_{h}^{J}$ falls slightly. This is the case as all wages fall due to the weakened bargaining power and the negative impact on low-skilled workers' wages is much larger than the negative impact on high-skilled workers as there is no direct negative impact on firms in the high-skilled sector.

Panel 6 shows that, as higher hiring costs in general reduce vacancy supply, all wages fall and unemployment increases due to lower transition rates for all workers. Panels 7-12 show that the impact on unemployment and wages from increasing the parameter values, when we have equal discrimination in both sectors, is similar to the impact when discrimination only exists in one sector. The next 12 panels show the impact of increasing discrimination to 0.5 for the two cases and confirm that nothing changes qualitatively.

Section 8.4 in the appendix provides a robustness test by changing all the parameter values significantly above 
and below the chosen values, but not more than that they still provide reasonable values for unemployment. The diagrams confirm robustness of our baseline findings with respect to the impact of discrimination. Varying the separation rate, $\sigma$, will raise or reduce the initial value of unemployment significantly, but the shown patterns for transition rates, wages and unemployment, still remain.

Figure 1: Transition rates

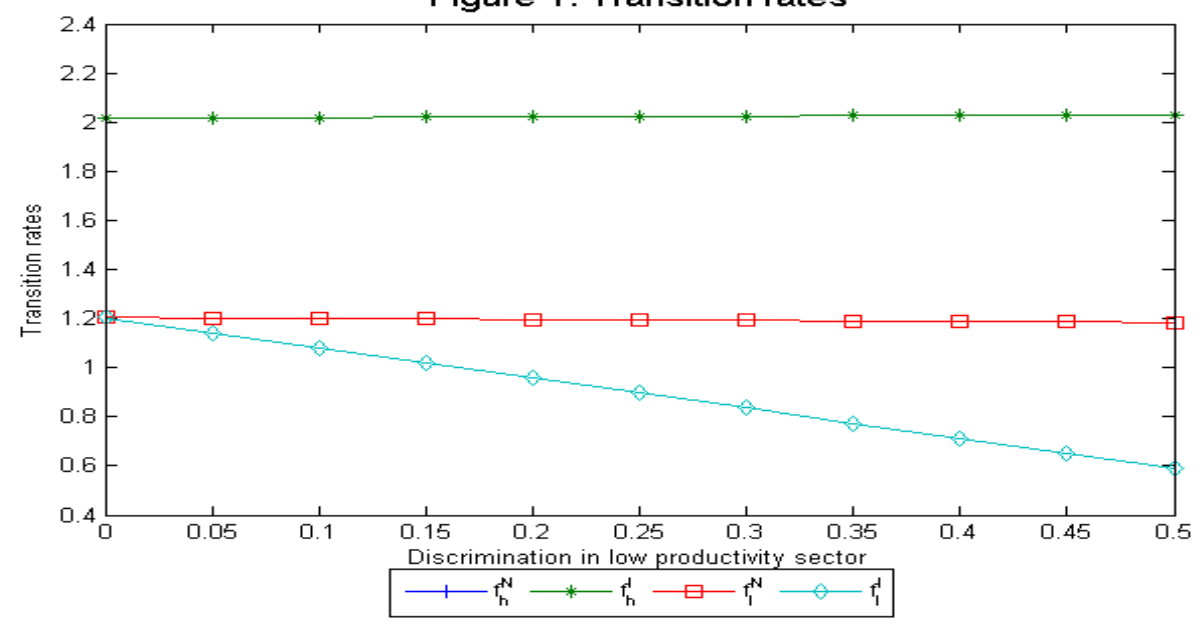

Figure 2: Unemployment

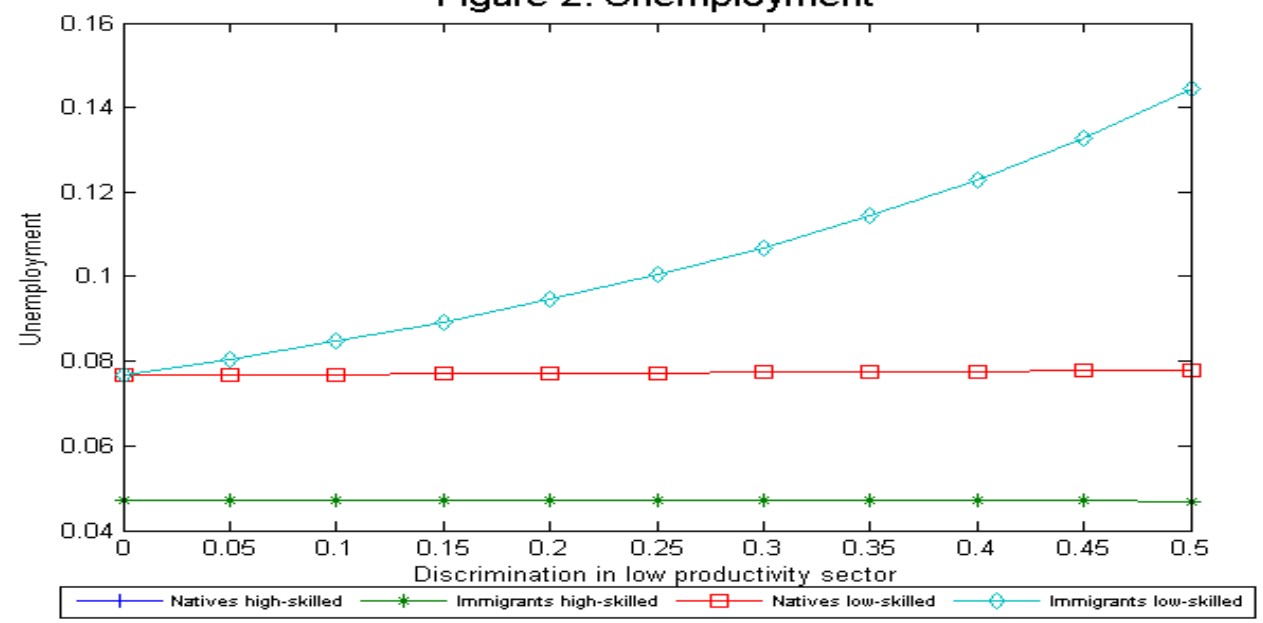


Figure 3: Wages

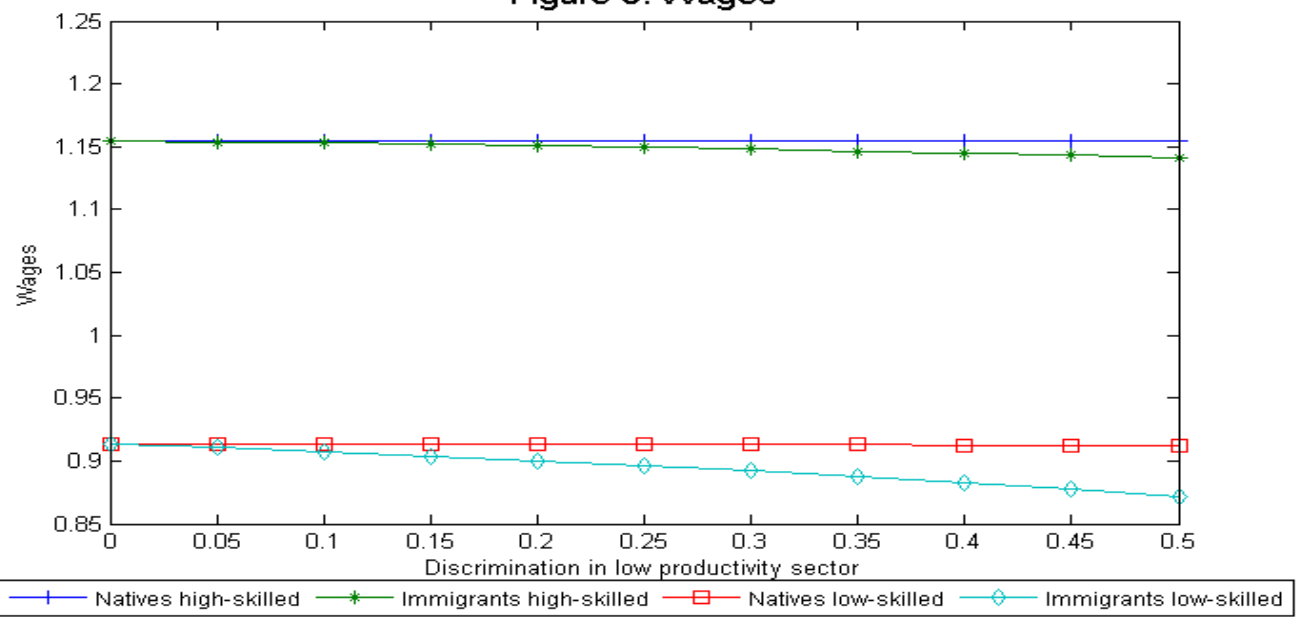

Figure 4: Transition rates

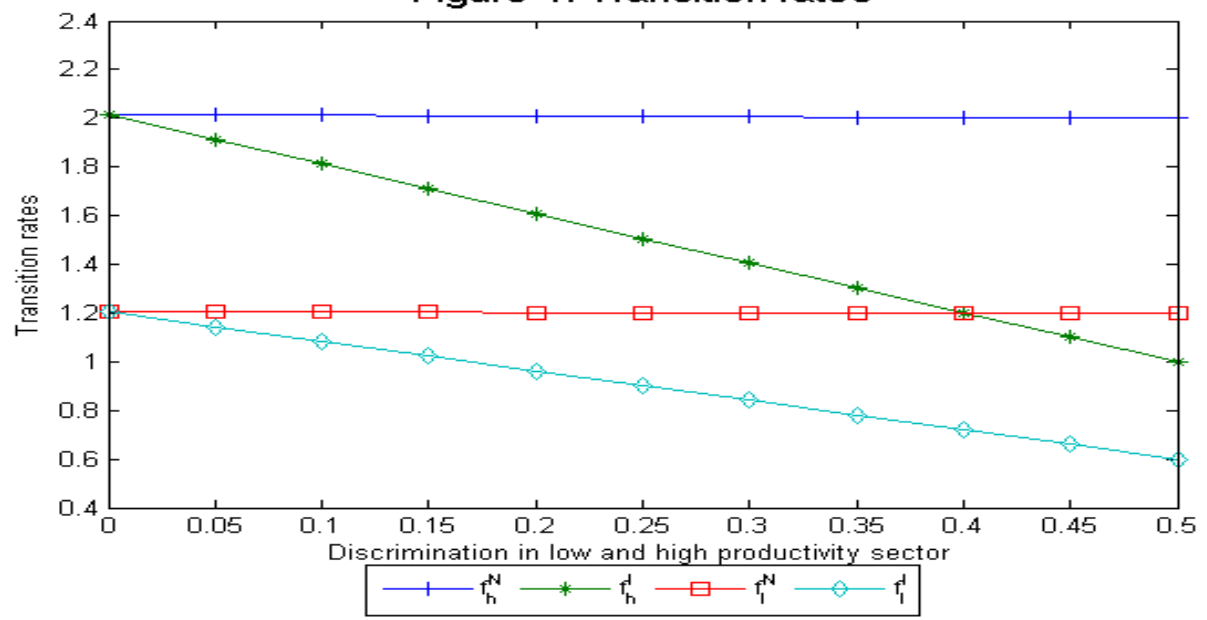

Figure 5: Unemployment

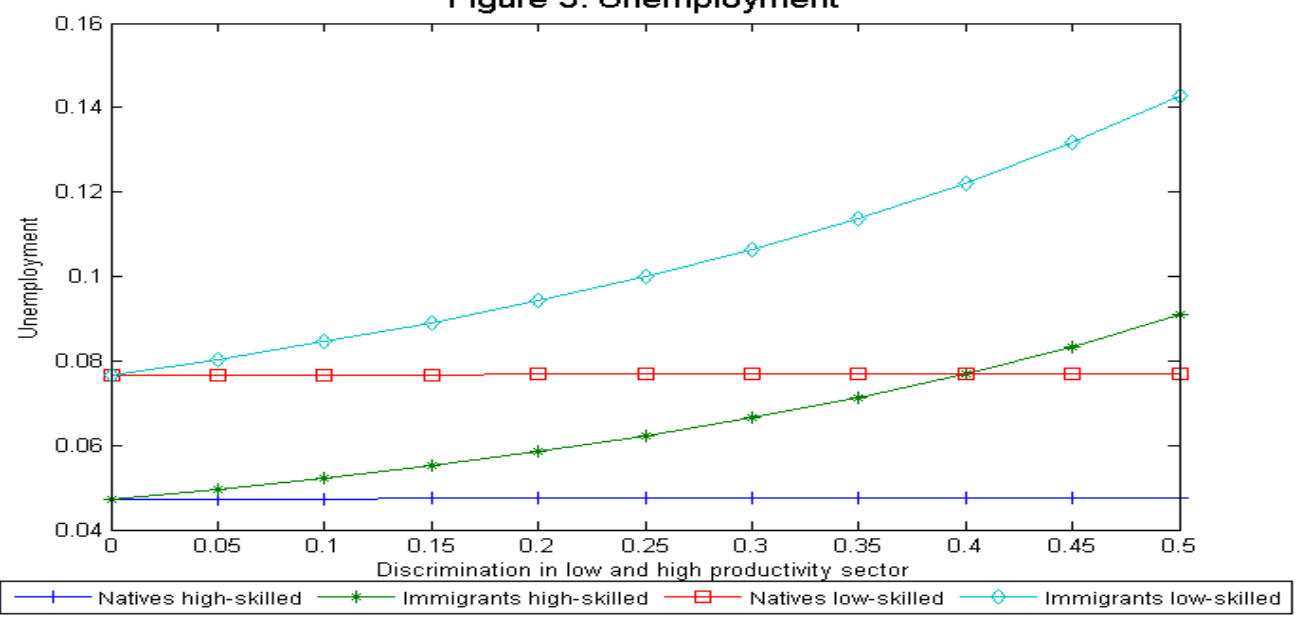


Figure 6: Wages

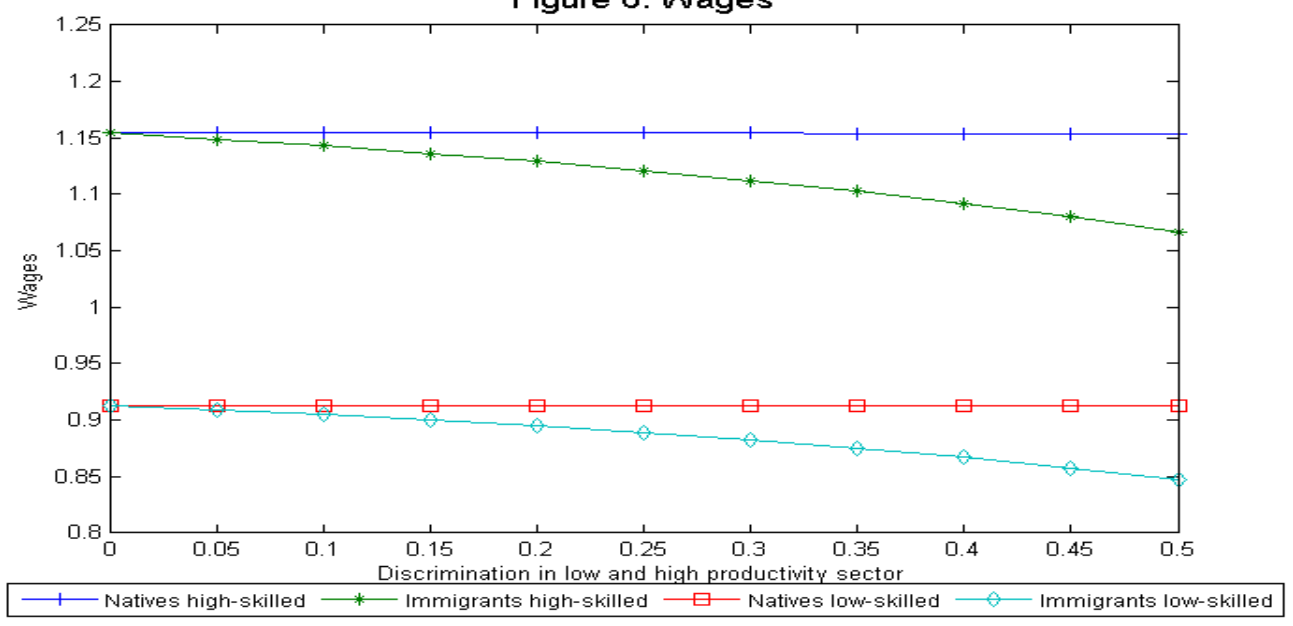

\section{CONCLUSION}

We formulated a model of discrimination against immigrants within a search and matching framework including high-skilled and low-skilled workers. First, we considered an equal number of high- and low-skilled workers for natives and immigrants, and examined the impact of higher discrimination on wages and unemployment. We showed that when there is only discrimination in the low-skilled sector, both native and immigrant low-skilled workers experience a wage reduction and higher unemployment whereas the high-skilled workers are unaffected. Equal discrimination in both sectors, on the other hand, implied that all workers were negatively affected, highskilled workers more severely so than low-skilled workers, as the transition rate for the former group of workers was the larger. We then extended the model to include loss of skill during unemployment as well as an exogenous probability of regaining skills, and again considered the impact of discrimination as well as immigration on labour market performance. We then obtained that discrimination in one sector affected the other sector as well and when discrimination was present in the low-skilled sector only, the employment perspectives of the high-skilled workers improved. When both sectors were affected by equal discrimination, high-skilled workers were worse off, whereas the impact on labour market performance for the low-skilled sector was ambiguous. Next, we considered endogenous skill choice as a response to loss of skill and evaluated how discrimination and immigration affected wages, unemployment as well as the fraction of skilled workers among natives and immigrants, respectively. We showed that higher discrimination in the low-skilled sector increased training of all workers, and the impact was stronger for immigrants than natives. The proportion of high-skilled immigrants was higher than the proportion of high-skilled natives, despite the fact that more immigrants became low-skilled workers due to discrimination and the risk of losing skills. Hence, a higher fraction of immigrants training than natives more than compensated for the negative impact on immigrants' skill level through loss of skill. Finally, we considered the impact of discrimination and immigration on net output and illustrative simulations for the model of loss of skill and exogenous training confirm our theoretical findings.

In conclusion, when considering the impact of discrimination on labour market performance given loss of skill during an unemployment experience, it is important to establish whether discrimination predominately exists in the sector employing low-skilled workers or in both sectors. This paper has revealed the theoretical results for the different cases. Future empirical research may confirm which cases are the most relevant to consider for different skill and ethnicity groups. 


\section{References}

[1] Acemoglu D. "Good Jobs versus Bad Jobs," Journal of Labor Economics, vol. 19(1), 2001, 1-21.

[2] Albrecht J. \& S. Vroman. "A Matching Model with Endogenous Skill Requirements," International Economic Review, vol. 43(1), 2002, 283-305.

[3] Arico F. "Both Sides of the Story: Skill-biased Technological Change, Labour Market Frictions, and Endogenous Two-Sided Heterogeneity." Centre for Dynamic Macroeconomic Analysis WP Series 0908, 2009.

[4] Battisti, M., G. Felbermayr, G. Peri, and P. Poutvaara. "Immigration, Search, and Redistribution: A Quantitative Assessment of Native Welfare." NBER Working Paper No. 20131, 2014.

[5] Bowlus A. J. and Z. Eckstein. "Discrimination and Skill Differences in an Equilibrium Search Model." International Economic Review, vol. 43(4), 2002, 1309-1345, November.

[6] Burdett K. \& E. Smith. "The low skill trap." European Economic Review, vol 46(8), 2002, 1439-1451.

[7] Chassamboulli A., and T. Palivos. "The Impact of Immigration on the Employment and Wages of Native Workers." Journal of Macroeconomics 38(Part A), 2013, pp. 19-34.

[8] Chassamboulli, A., and T. Palivos. "A Search-Equilibrium Approach to the Effects of Immigration on Labor Market Outcomes." International Economic Review 55(1), 2014, pp. 111-129.

[9] Chassamboulli, A., and G. Peri. "The Labor Market Effects of Reducing Undocumented Immigrants." NBER Working Paper No 19932, 2014.

[10] Davila A. \& M. Mora. "Changes in the Earnings of Arab Men in the US between 2000 and 2002." Journal of Population Economics, 18(4), 2005, 587-601.

[11] http://ec.europa.eu/eurostat.

[12] Engström P., B. Holmlund \& A. S. Kolm. "Tax Differentiation, Search Unemployment, and Home Production." Oxford Economic Papers, 57, 2005, 610-633.

[13] Flabbi, L. "Gender Discrimination Estimation In A Search Model With Matching And Bargaining." International Economic Review, vol. 51(3), 2010, 745-783, 08.

[14] Hosios, A. "On the Efficiency of Matching and Related Models of Search and Unemployment." Review of Economic Studies, Wiley Blackwell, vol. 57(2), 2000, 279-98. 
[15] Kaushal N., R. Kaestner \& C. Reimers. "Labor Market Effects of September 11th on Arab and Muslim Residents of the U.S." Journal of Human Resources 42(2), 2007, 275-308.

[16] Lang, K., M. Manove and W. T. Dickens. "Racial Discrimination in Labor Markets with Posted Wage Offers." American Economic Review, vol. 95(4), 2005, 1327-1340, September.

[17] Larsen, B. "Minimum Wages, Technological Progress and Loss of Skill." European Economic Review 45, 2001, p. $1521-544$.

[18] Larsen, B. and G. Waisman. "Labour Market Performance Effects of Discrimination and Loss of Skill." Working Paper, Copenhagen Business School, 2015.

[19] Liu, X. "On the Macroeconomic and Welfare Effects of Illegal Immigration." Journal of Economic Dynamics and Control 34(12), 2010, pp. 2547-2567.

[20] Mailath, G. J., L. Samuelson and A. Shaked. "Endogenous Inequality in Integrated Labor Markets with TwoSided Search." American Economic Review, vol. 90(1), 2000, 46-72, March.

[21] Millard S.P. and D. T. Mortensen. "The Unemployment and Welfare Effects of Labour Market Policy: A Comparison of the USA and UK. In: Snower D. and G. de la Dehesa, eds., Unemployment Policy: Government Options for the Labour Market." Oxford University Press, Oxford, 1997.

[22] www.oecd.org.

[23] Pissarides C.A. "Unemployment and vacancies in Britain" Economic Policy, 3, 1986, 499-559.

[24] Pissarides C. A. "Equilibrium Unemployment Theory", Cambridge, MIT. 2000.

[25] Rabby, F. and W. M. Rodgers. "Post 9-11 U.S. Muslim Labor Market Outcomes." Atlantic Economic Journal 39(3), 2011, 273-289.

[26] www.scb.se.

[27] Zussman, A. and M. Shayo. "Judicial Ingroup Bias in the Shadow of Terrorism." The Quarterly Journal of Economics, Oxford University Press, vol. 126(3), 2011, 1447-1484.

\section{APPENDIX}

\subsection{Condition for Values, No Loss of Skill}

In this appendix we derive a condition for when $r U_{h}^{J}>r E_{l}^{J}$, that is that the value of being a skilled unemployed worker is higher than the value of being a low-skilled worker. 
The value equations are given by equations (1) and (2), inserting for wages from equations (6) giving the solutions

$$
\rho U_{s}^{J}=\frac{f_{s}^{J}}{2(\rho+\sigma)+f_{s}^{J}} y_{h}, \rho E_{s}=\frac{\rho+f_{s}^{J}}{2(\rho+\sigma)+f_{s}^{J}} y_{l}, s=h, l, J=N, I .
$$

In the first case where $d_{h}=0$ and $d_{l}>0$, the value of being a skilled unemployed worker is higher than the value of being a low-skilled worker for both natives and immigrants, $r U_{h}^{I}=r U_{h}^{N}>r E_{l}^{N}>r E_{l}^{I}$, if and only if

$$
\frac{f_{h}}{2(\rho+\sigma)+f_{h}} y_{h}>\frac{\rho+f_{l}}{2(\rho+\sigma)+f_{l}} y_{l} \Leftrightarrow \frac{y_{h}}{y_{l}}>\frac{\rho+f_{l}}{f_{h}} \frac{2(\rho+\sigma)+f_{h}}{2(\rho+\sigma)+f_{l}} .
$$

As $\frac{2(\rho+\sigma)+f_{h}}{2(\rho+\sigma)+f_{l}}<\frac{\sigma+f_{h}}{\sigma+f_{l}}$ as sufficient condition is

$$
\frac{y_{h}}{y_{l}}>\frac{\sigma}{f_{h}}+1=\frac{\frac{\sigma}{\sigma+f_{h}}}{\frac{f_{h}}{\sigma+f_{h}}}+1=\frac{u_{h}^{N}}{e_{h}^{N}}+1 .
$$

Hence for unemployment relative to employment less than a quarter, the condition becomes $y_{h} / y_{l}>1.25$.

In the second case where $d_{h}=d_{l}=d>0$, then $r U_{h}^{N}>r E_{l}^{N}$ giving the same condition as above and $r U_{h}^{I}>r E_{l}^{I}$ if and only if

$$
\frac{f_{h}(1-d)}{2(\rho+\sigma)+f_{h}(1-d)} y_{h}>\frac{\rho+f_{l}(1-d)}{2(\rho+\sigma)+f_{l}(1-d)} y_{l} \Leftrightarrow \frac{y_{h}}{y_{l}}>\frac{\rho+f_{l}(1-d)}{f_{h}(1-d)} \frac{2(\rho+\sigma)+f_{h}(1-d)}{2(\rho+\sigma)+f_{l}(1-d)} .
$$

As $\frac{2(\rho+\sigma)+f_{h}(1-d)}{2(\rho+\sigma)+f_{l}(1-d)}<\frac{\sigma+f_{h}(1-d)}{\sigma+f_{l}(1-d)}$ as sufficient condition is

$$
\frac{y_{h}}{y_{l}}>\frac{\sigma}{f_{h}(1-d)}+1=\frac{\frac{\sigma}{\sigma+f_{h}(1-d)}}{\frac{f_{h}(1-d)}{\sigma+f_{h}(1-d)}}+1=\frac{u_{h}^{I}}{e_{h}^{I}}+1 .
$$

Hence the same condition applies as above.

\subsection{The Equations for The Model with Skill Loss and Exogenous Training and with Different Separation Rates}

When we assume we have two different separation rate for high- and low-skilled workers, $\sigma_{h}$ and $\sigma_{l}$, the model becomes more complex. As in the other simulations, we assume that $\alpha=0.5$. The equations for labour market tightness are now given by

$$
\begin{gathered}
\left.k f_{h}\left(\rho+\sigma_{h}\right)-\phi\left(y_{h}-w_{h}^{N}\right)-(1-\phi)\left(1-d_{h}\right)\left(y_{h}-w_{h}^{I}\right)\right)=0 \\
\left.k f_{l}\left(\rho+\sigma_{l}\right)-\phi\left(y_{l}-w_{l}^{N}\right)-(1-\phi)\left(1-d_{l}\right)\left(y_{l}-w_{l}^{I}\right)\right)=0 .
\end{gathered}
$$

The wage equations becomes

$$
w_{h}^{J}=\frac{\lambda f_{l}^{J} y_{l}+y_{h}\left(2 \frac{\rho+\sigma_{l}}{\rho+\sigma_{h}}\left(\mu\left(\rho+\sigma_{h}\right)+f_{h}^{J}(\rho+\gamma)\right)+f_{l}^{J}\left((\rho+\lambda)+f_{h}^{J} \frac{\rho}{\rho+\sigma_{h}}\right)\right)}{\left(2 \frac{\rho+\sigma_{l}}{\rho+\sigma_{h}}\left(2 \mu\left(\rho+\sigma_{h}\right)+f_{h}^{J}(\rho+\gamma)\right)+f_{l}^{J}(2(\lambda+\rho))+\frac{\rho}{\rho+\sigma_{h}} f_{h}^{J}\right)}
$$




$$
w_{l}^{J}=\frac{\gamma f_{h}^{J} \frac{\rho+\sigma_{l}}{\rho+\sigma_{h}} y_{h}+y_{l}\left(2 \mu\left(\rho+\sigma_{l}\right)+f_{h}^{J}(\gamma+\rho) \frac{\rho+\sigma_{l}}{\rho+\sigma_{h}}+f_{l}^{J}\left(2(\rho+\lambda)+\frac{\rho}{\rho+\sigma_{h}} f_{h}^{J}\right)\right)}{2 \frac{\rho+\sigma_{l}}{\rho+\sigma_{h}}\left(2 \mu\left(\rho+\sigma_{h}\right)+f_{h}^{J}(\rho+\gamma)\right)+f_{l}^{J}(2(\lambda+\rho))+\frac{\rho}{\rho+\sigma_{h}} f_{h}^{J}}
$$

where $f_{h}=f_{h}^{N}, f_{l}^{N}=f_{l}$ and $f_{h}^{I}=f_{h}\left(1-d_{h}\right)$ and $f_{l}^{I}=f_{l}\left(1-d_{l}\right)$ and where $\mu=(\rho+\lambda+\gamma)$. We also obtain the the proportion of natives among the high- and low-skilled workers

$$
\phi_{h}=\frac{1}{1+\frac{(1-n)}{n} \frac{\left(\sigma_{h}+f_{h}^{N}+\left(\frac{\sigma_{h}}{\sigma_{l}} f_{l}^{N}+\sigma_{h}\right) \frac{\lambda}{\gamma}\right)}{\left(\sigma_{h}+f_{h}^{I}+\left(\frac{\sigma_{h}}{\sigma_{l}} f_{l}^{I}+\sigma_{h}\right) \frac{\lambda}{\gamma}\right)}}=\phi_{l}=\phi .
$$

The unemployment rates change to

$$
u_{h}^{J}=\frac{\sigma_{h}}{f_{h}^{J}+\sigma_{h}}, u_{l}^{J}=\frac{\sigma_{l}}{f_{l}^{J}+\sigma_{l}}, \quad J=N, I .
$$




\subsection{Impact on Equilibrium Values of Changing Parameter Values}

The next 12 figures consider case 1 where $d_{h}=0, d_{l}=0.20$ and the same parameter values as original chosen. We then vary one parameter at a time keeping the other values fixed.
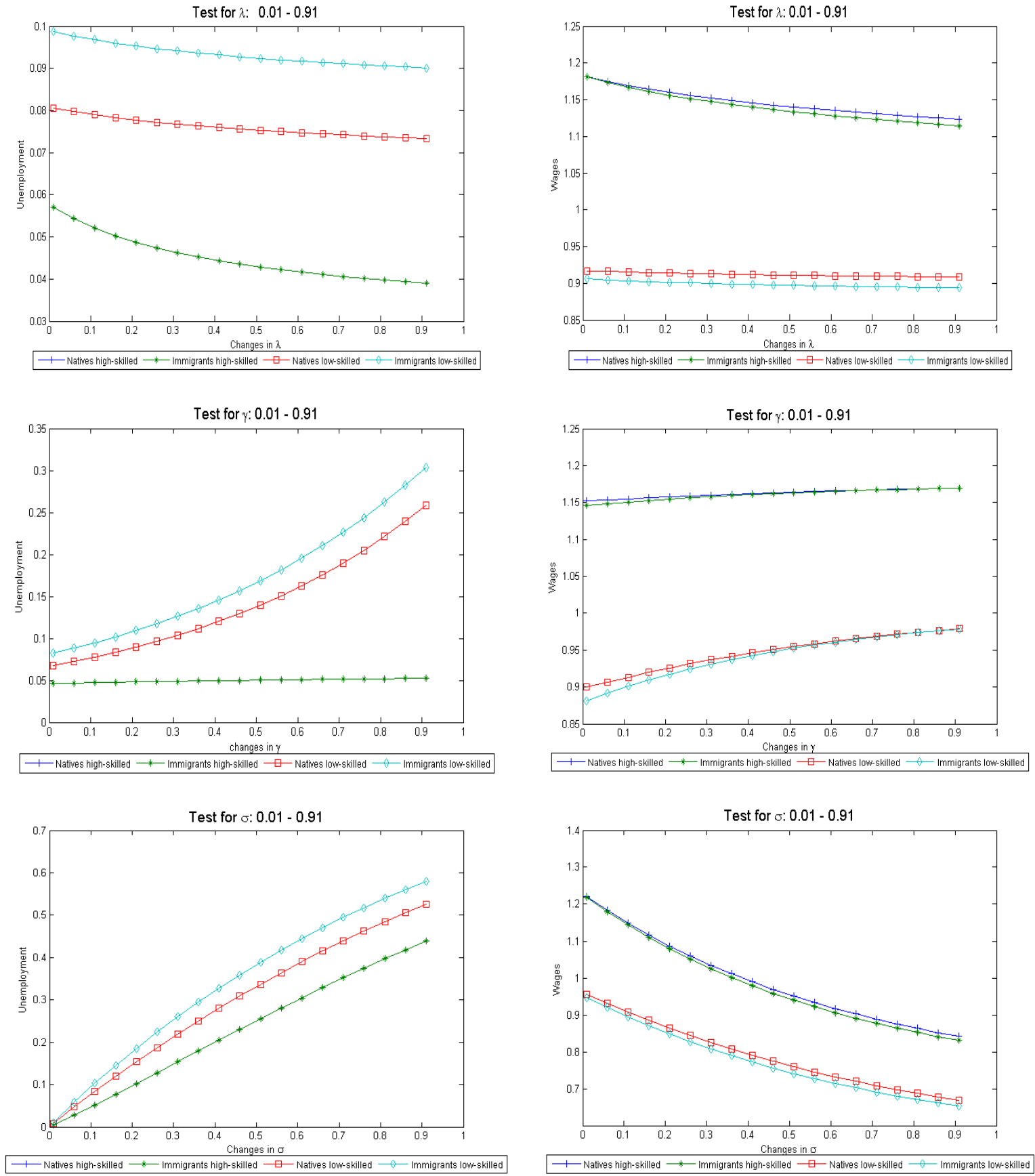

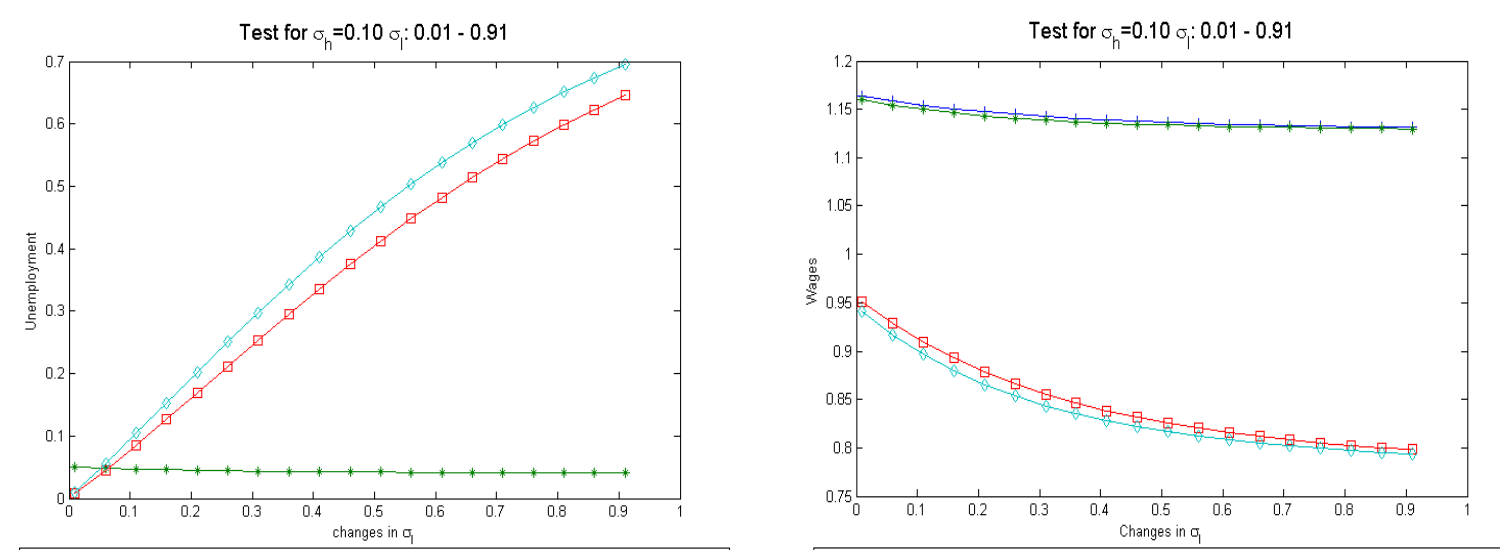

$\longrightarrow$ - Natives high-skilled $\rightarrow$ * Immigrants high-skilled $\rightarrow$ 口- Natives low-skilled $\longrightarrow-$ - Immigrants low-skilled
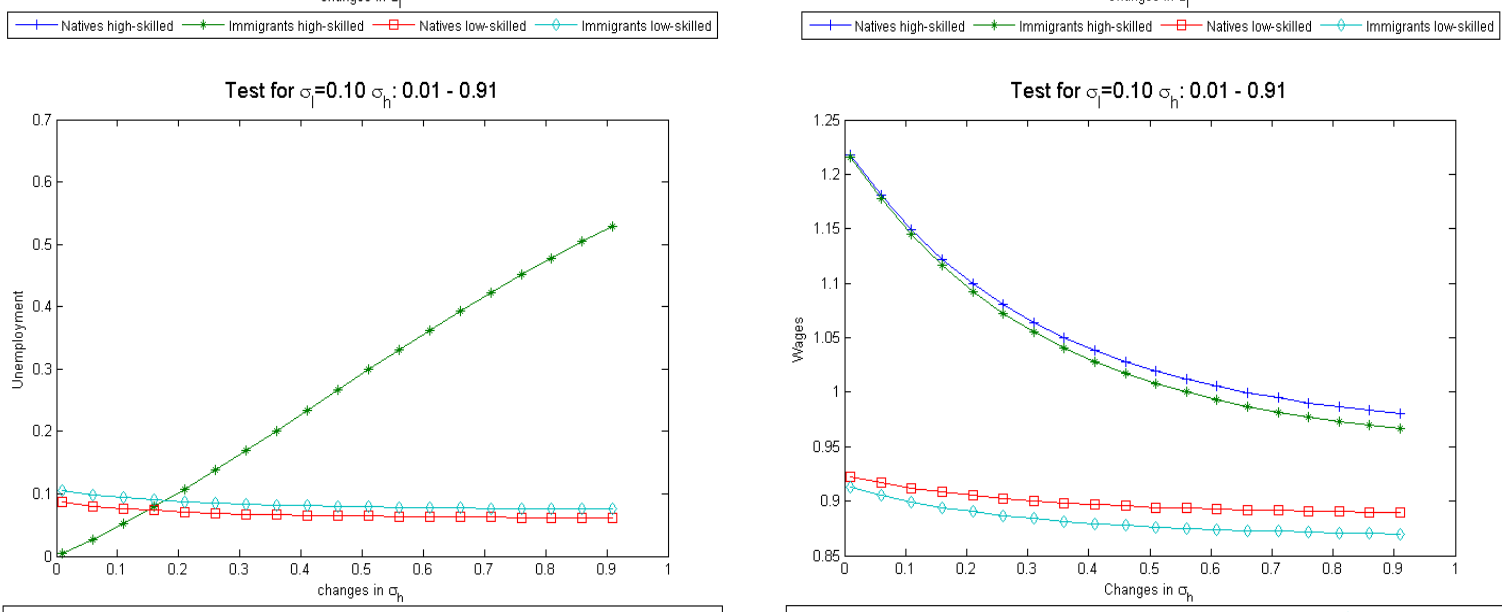

—— Natives high-skilled $\longrightarrow$ * Immigrants high-skilled $\longrightarrow$ 口-Natives low-skilled $\longrightarrow 0$ Immigrants low-skilled
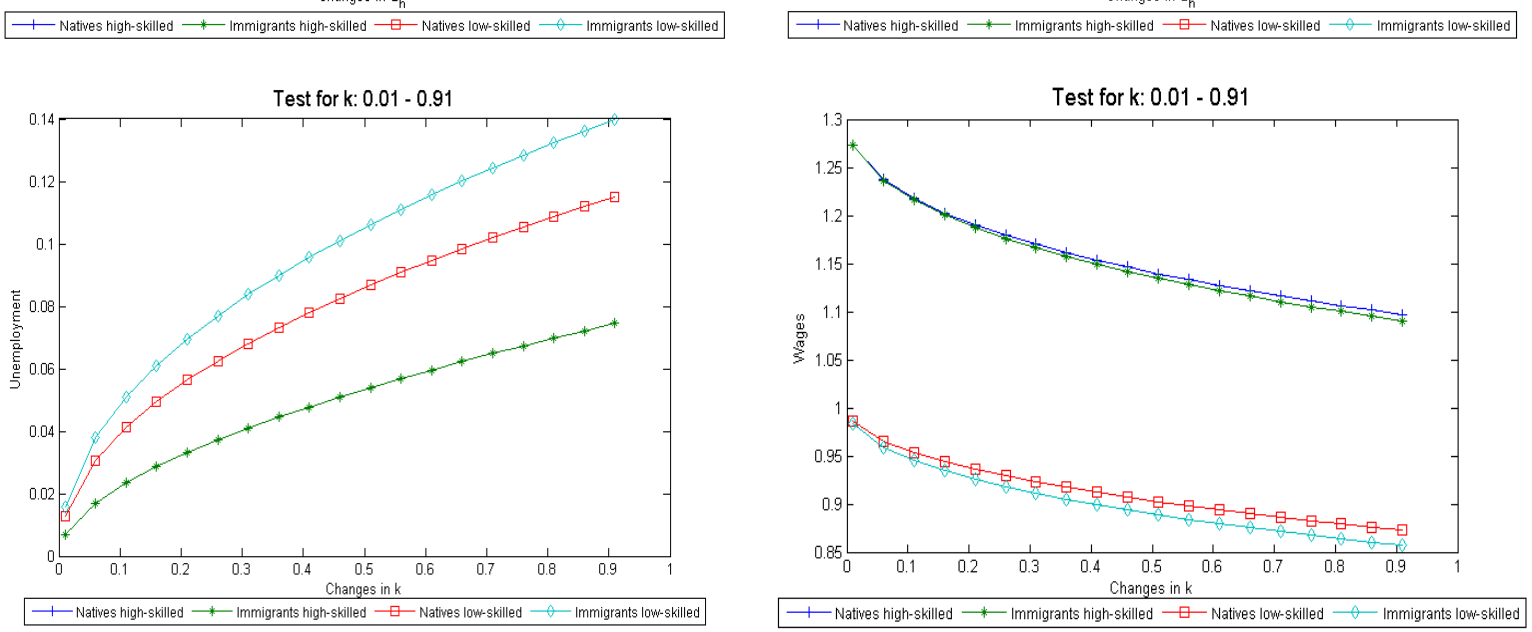
The next 12 figures consider case 2 where $d_{h}=0.20, d_{l}=0.20$ and the same parameter values as original chosen. We then vary one parameter at a time keeping the other values fixed.
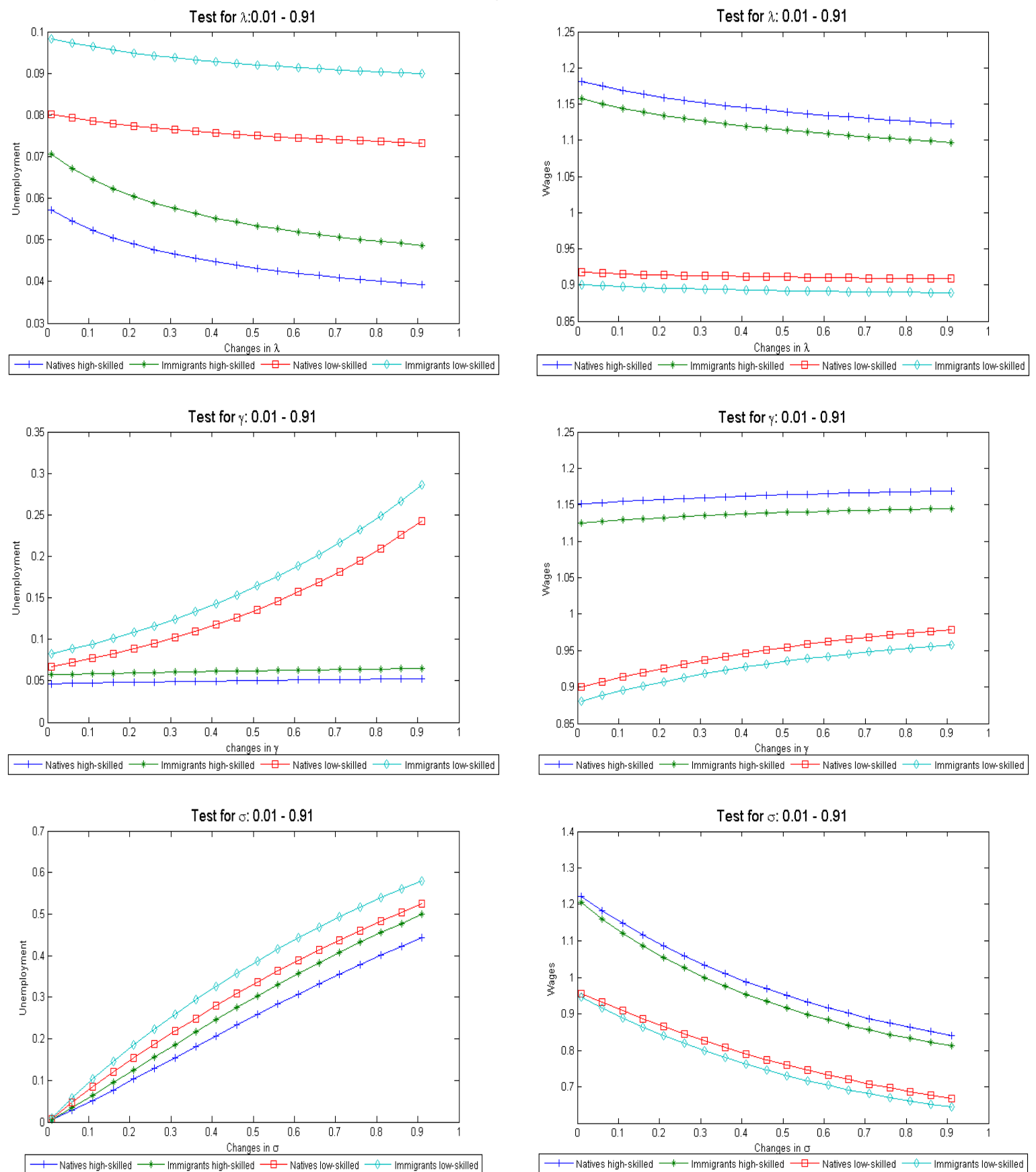

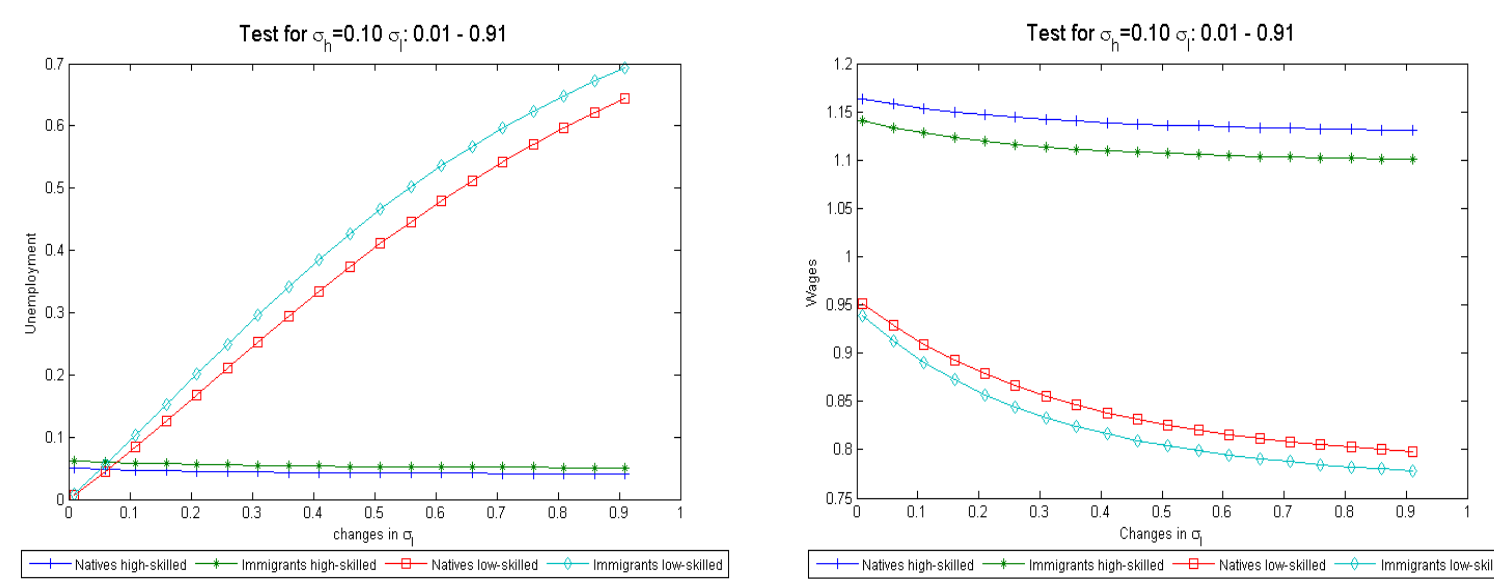

$\longrightarrow$ Natives high-skilled $\rightarrow$ - Immigrants high-skilled $\longrightarrow$ - Natives low-skilled $\rightarrow$ - Immigrants low-skilled
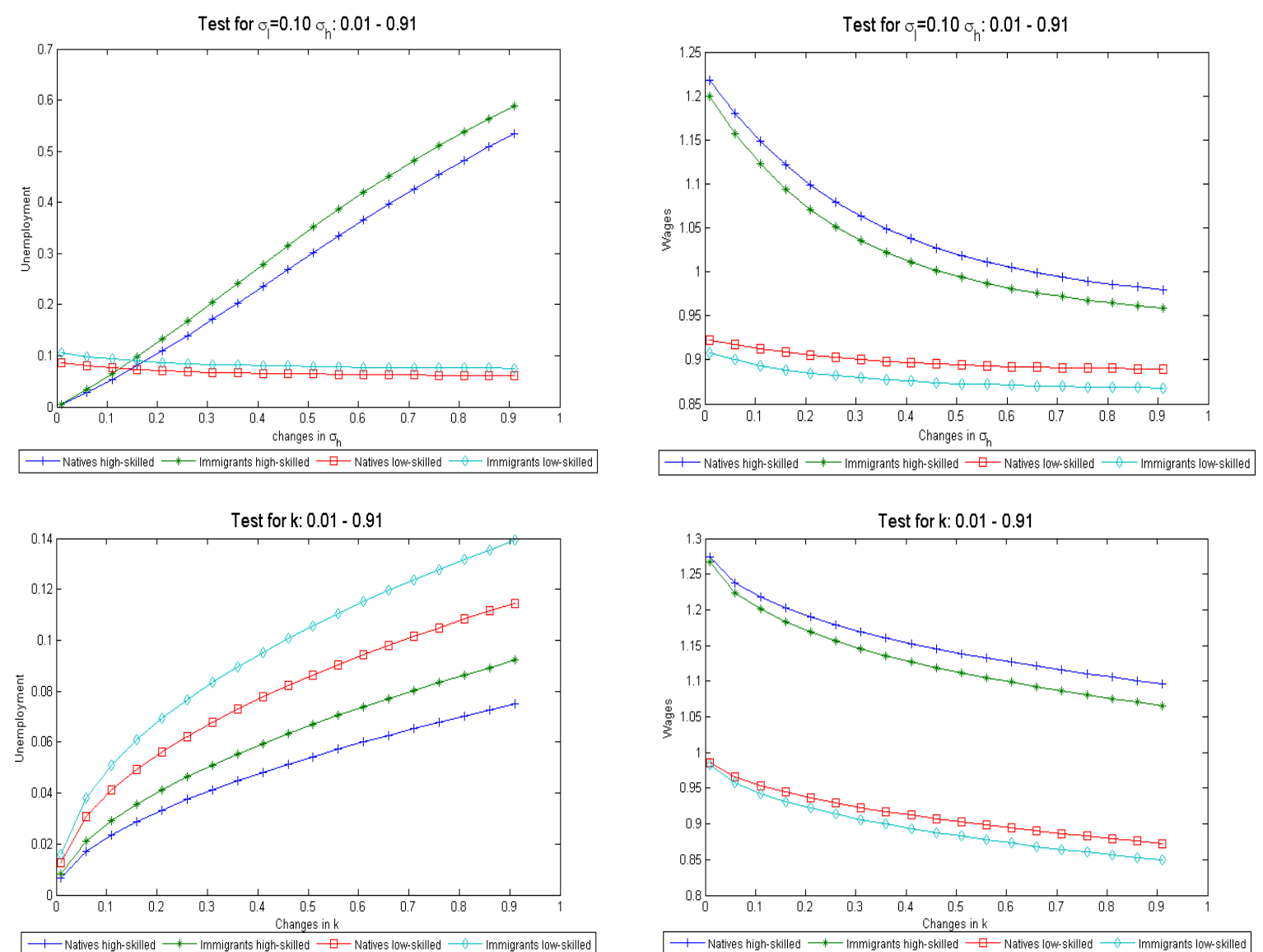
The next 12 figures consider case 1 where $d_{h}=0, d_{l}=0.50$ and the same parameter values as original chosen. We then vary on parameter at a time keeping the other values fixed.
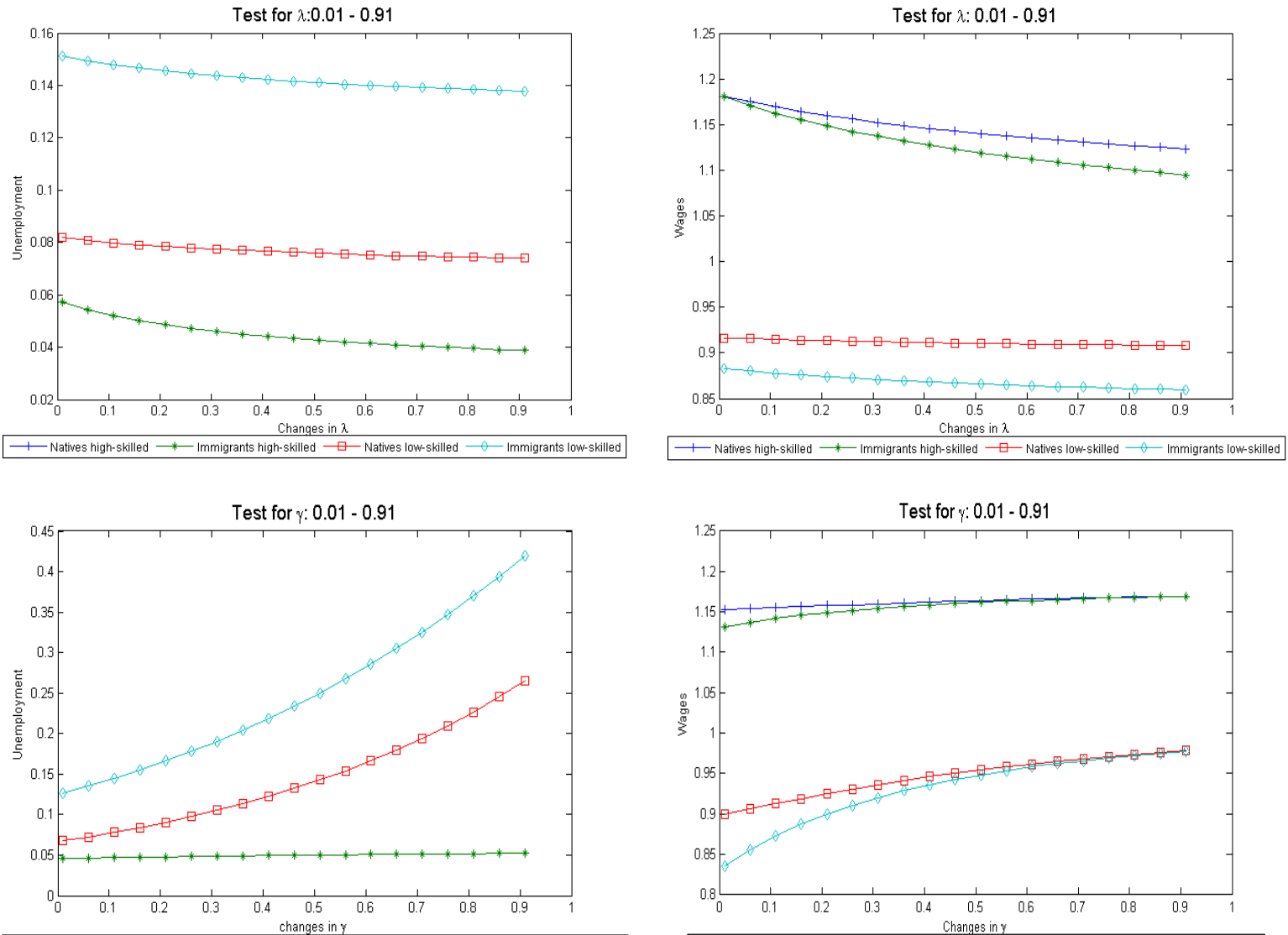

Natives high-skilled $\rightarrow *$ Immigrants high-skilled $\rightarrow$ - Natives low-skilled $\longrightarrow 0$ Immigrants low-skilled
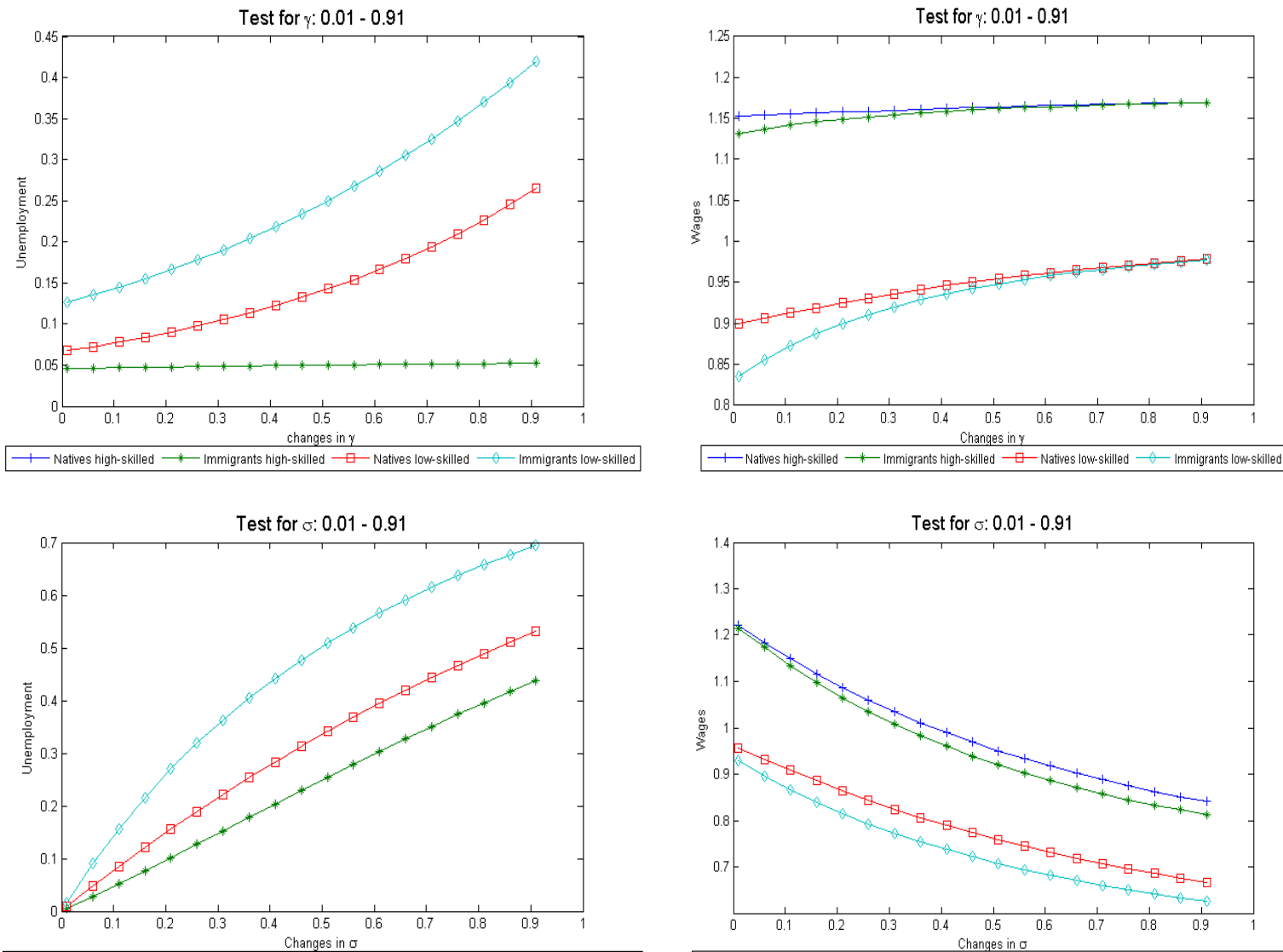

Natives high-skilled $\rightarrow-$ Immigrants high-skilled $\rightarrow$ Natives low-skilled $\rightarrow 0$ Immigrants low-skilled

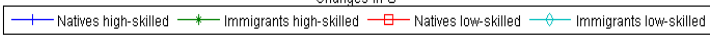



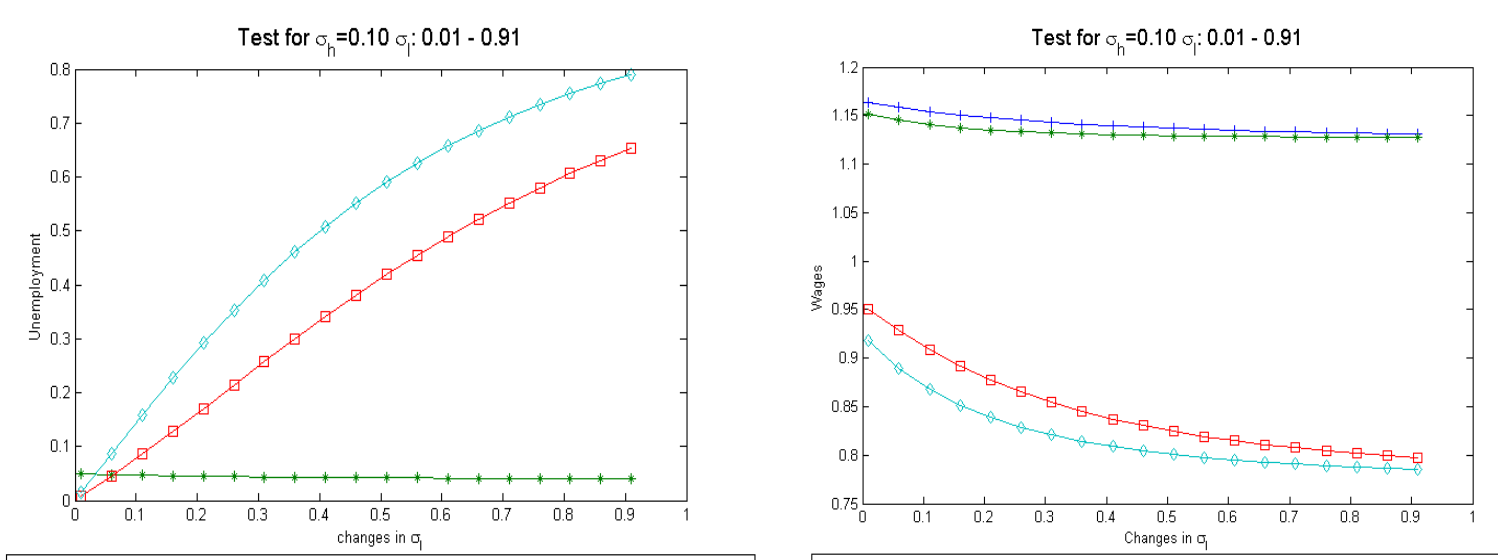

$\longrightarrow$ Natives high-skilled $\rightarrow$ - Immigrants high-skilled $\rightarrow \square-$ Natives low-skilled $\rightarrow 0$ Immigrants low-skilled

$\longrightarrow$ - Natives high-skilled $\rightarrow-$ Immigrants high-skilled $\longrightarrow$ 口- Natives low-skilled $\rightarrow 0$ Immigrants low-skilled
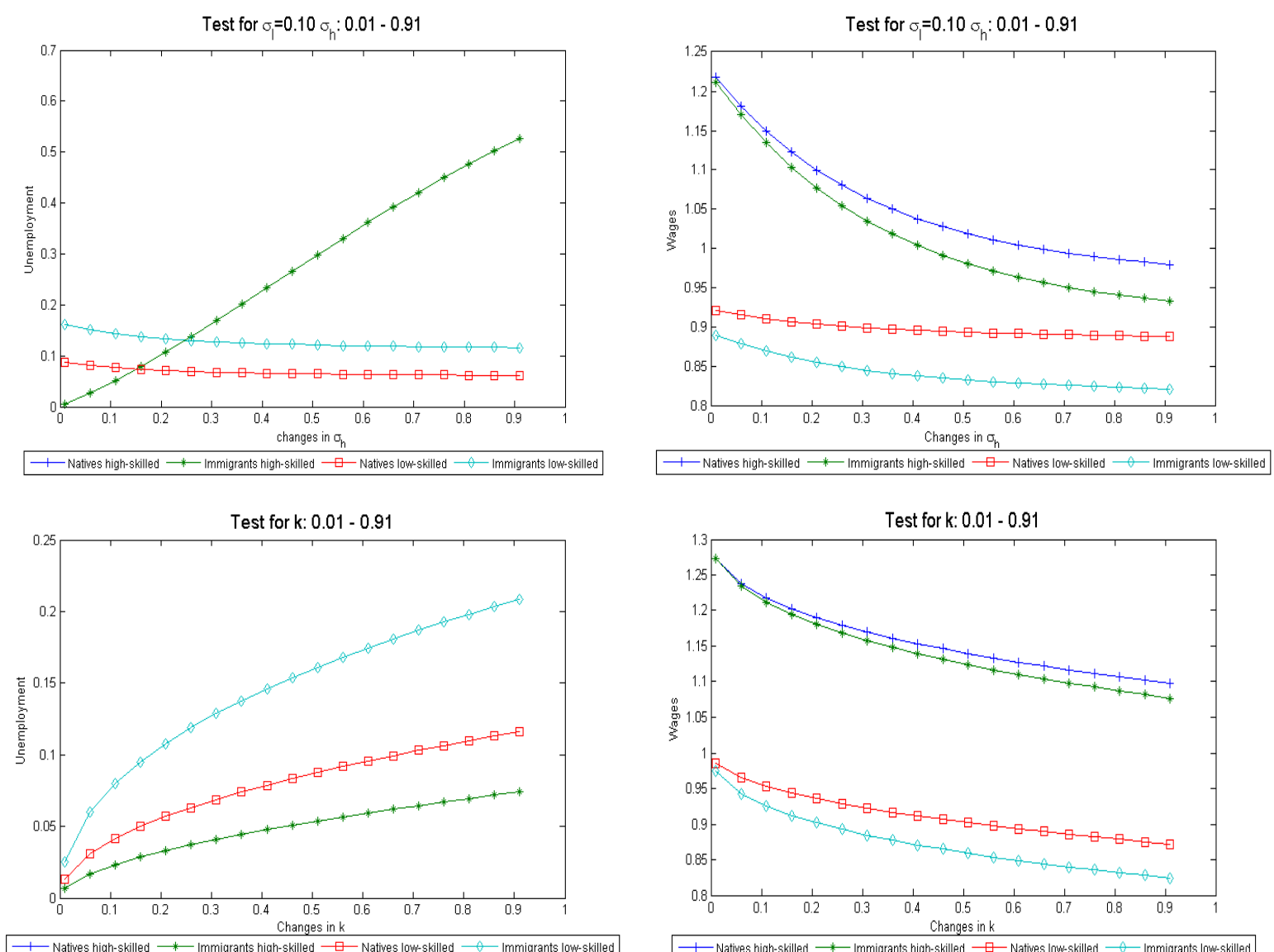
The next 12 figures consider case 2 where $d_{h}=0.50, d_{l}=0.50$ and the same parameter values as original chosen. We then vary on parameter at a time keeping the other values fixed.
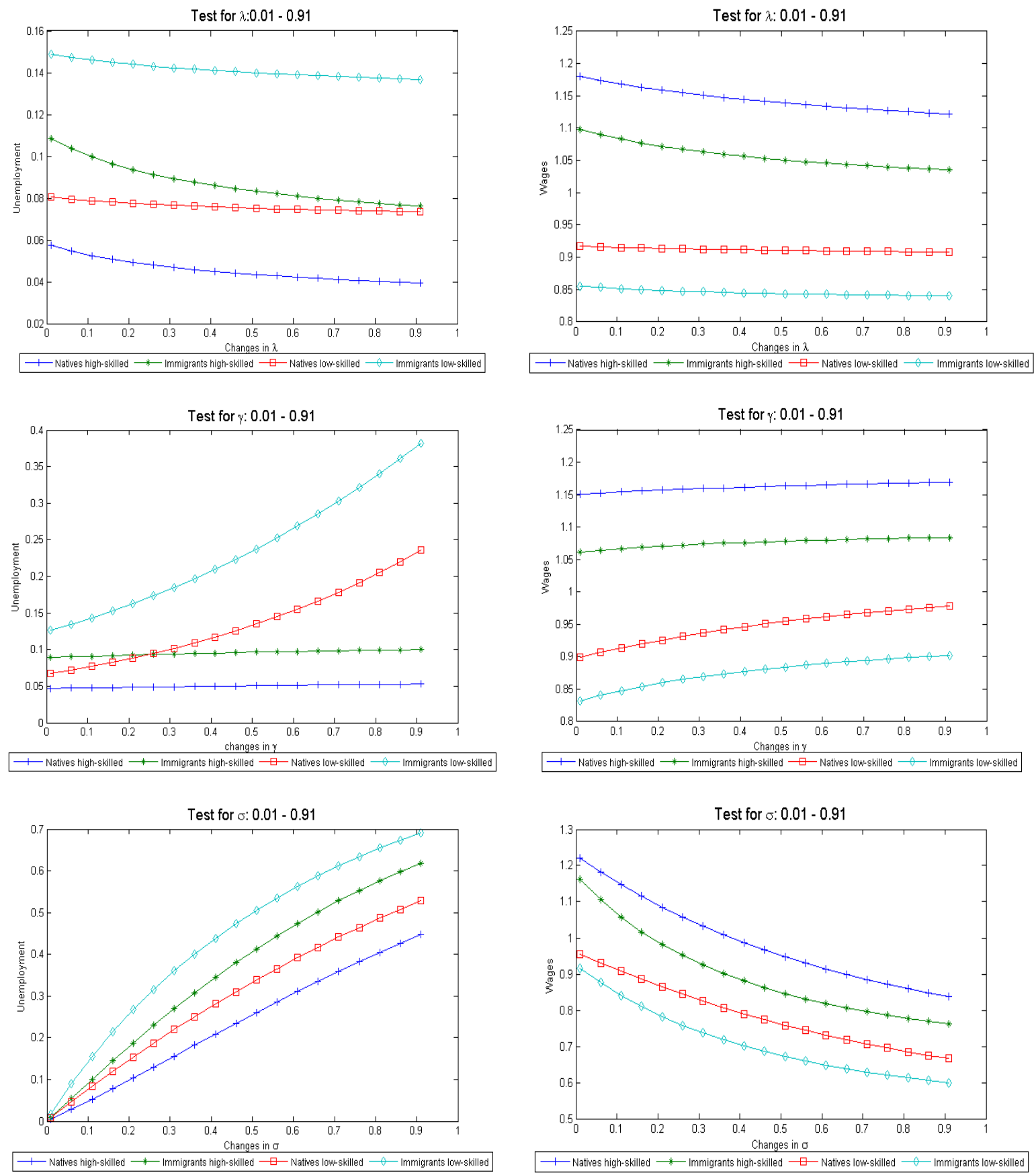

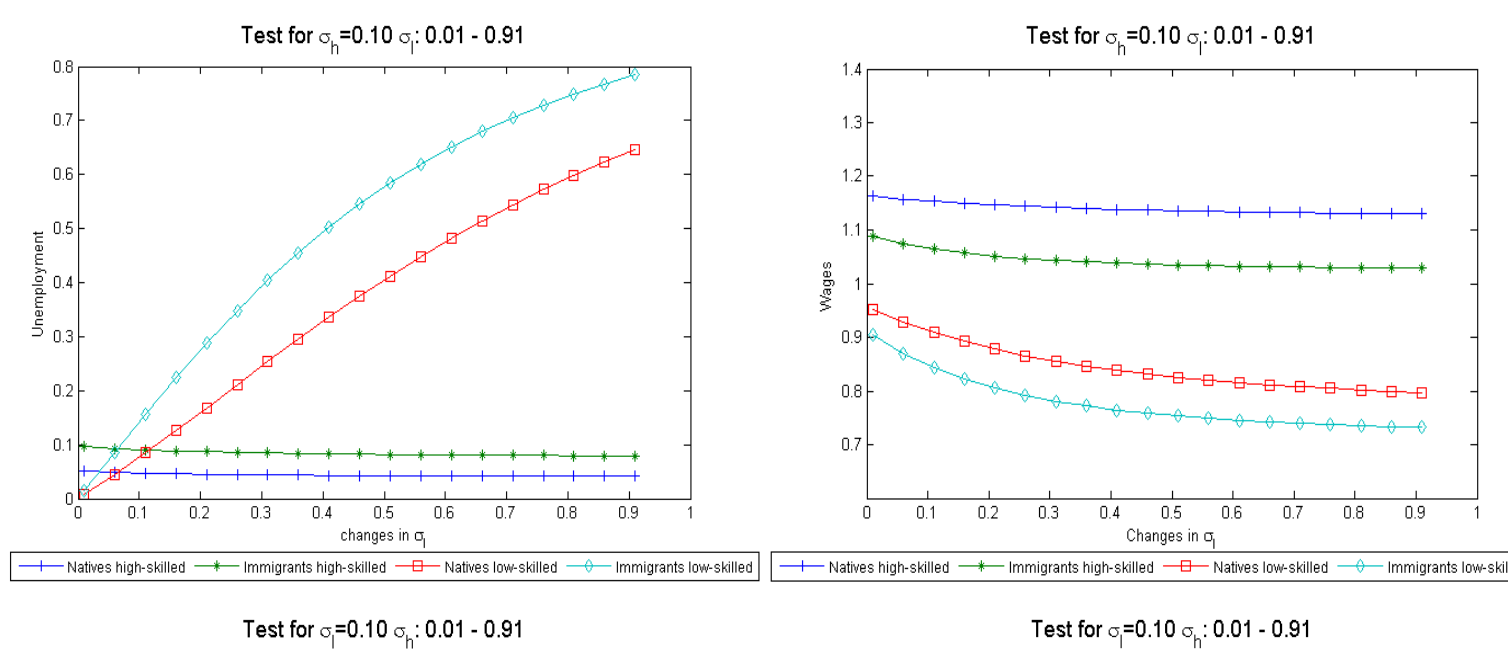

—— Natives high-skilled $\rightarrow$ * Immigrants high-skilled $\longrightarrow$ 口-Natives low-skilled $\rightarrow 0$ Immigrants low-skilled
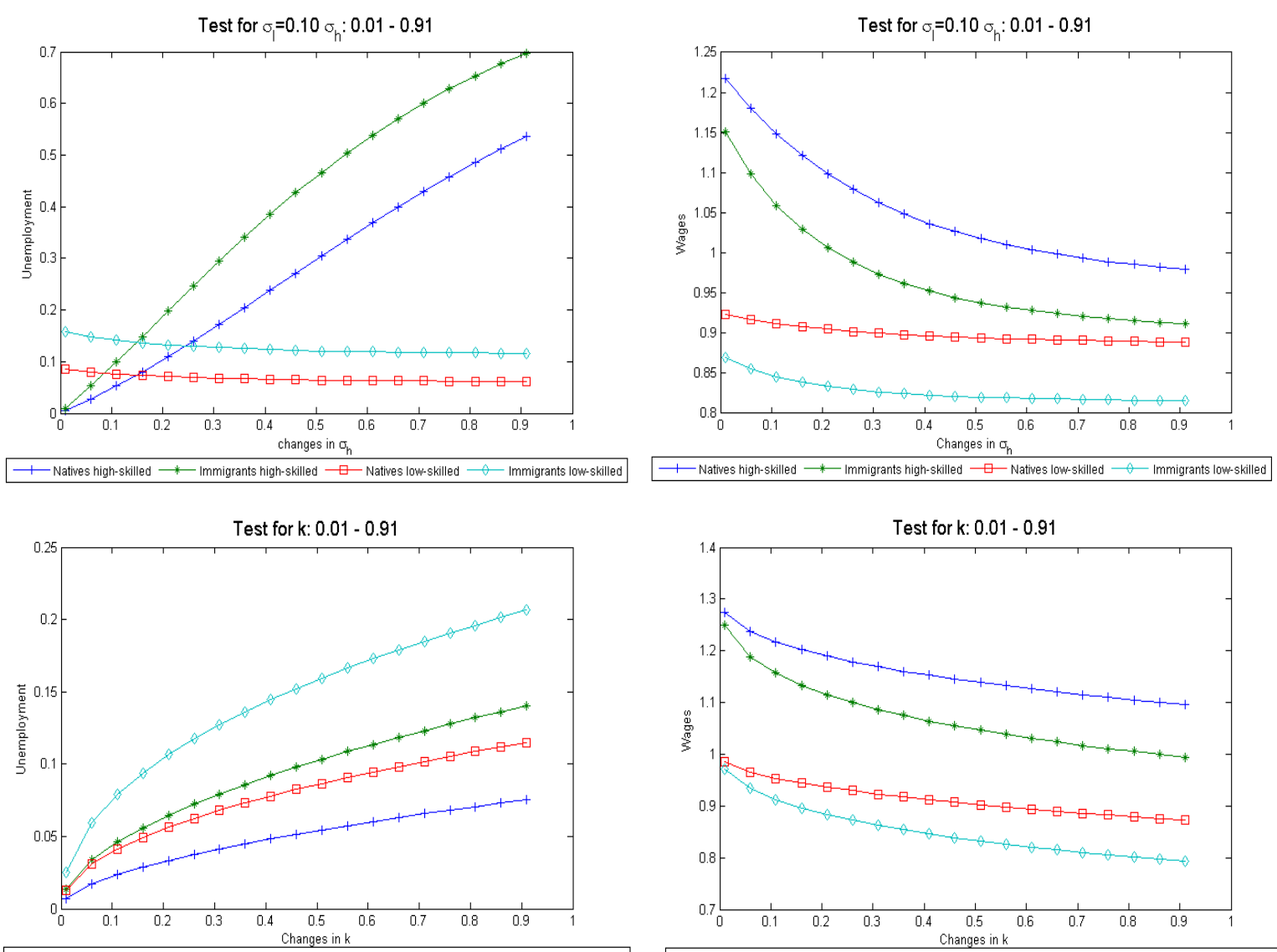

1 Natives high-skilled $\rightarrow$ * Immigrants high-skilled $\square-$ Natives low-skilled $\rightarrow-$ Immigrants low-skilled

$\longrightarrow$ Natives high-skilled $\longrightarrow *$ Immigrants high-skilled —-Natives low-skilled —o Immigrants low-skilled 


\subsection{Robustness Test}

The next 36 figures in this section consider case 1 where $d_{h}=0$ and $d_{l}=0.00-0.50$.
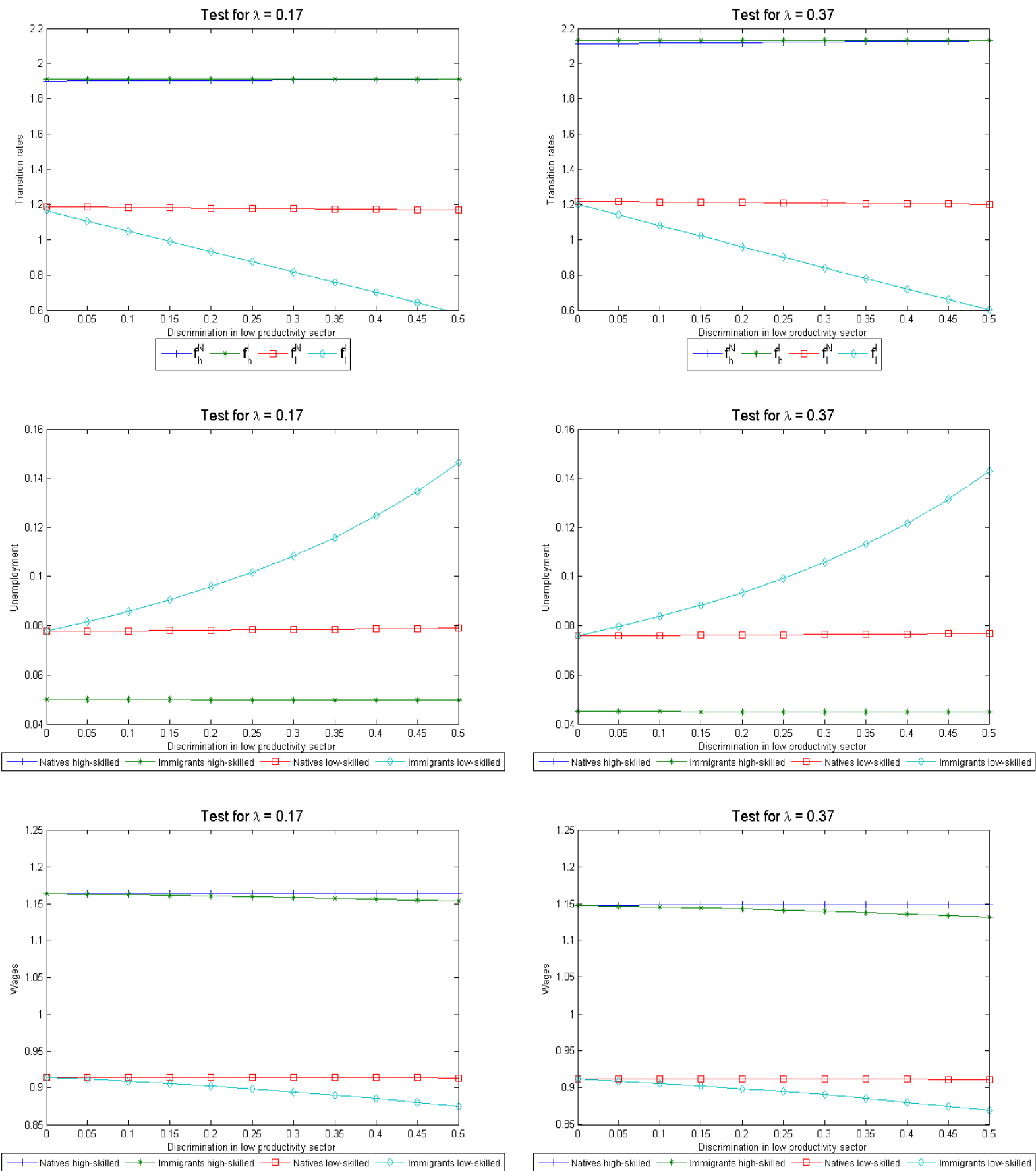

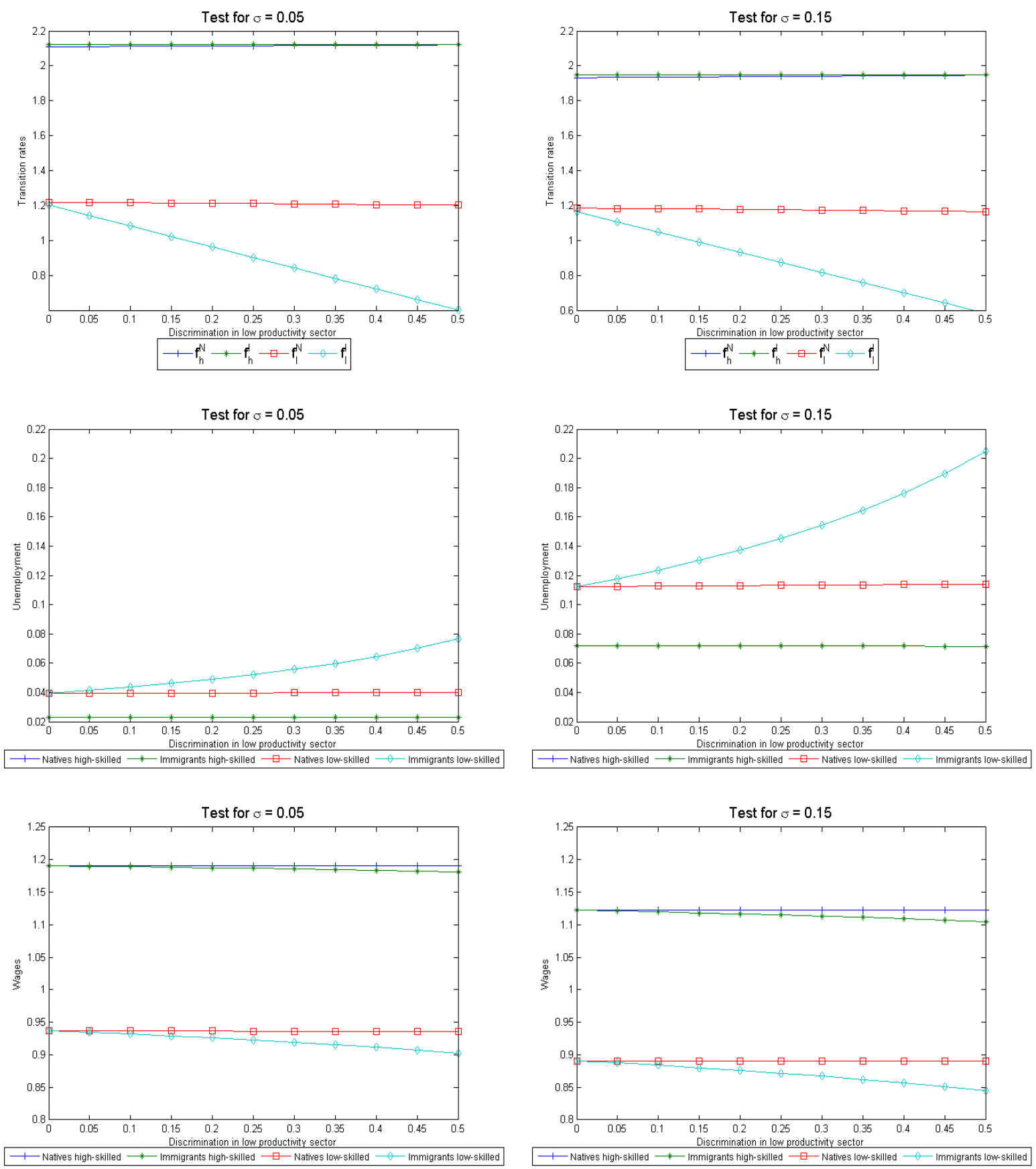

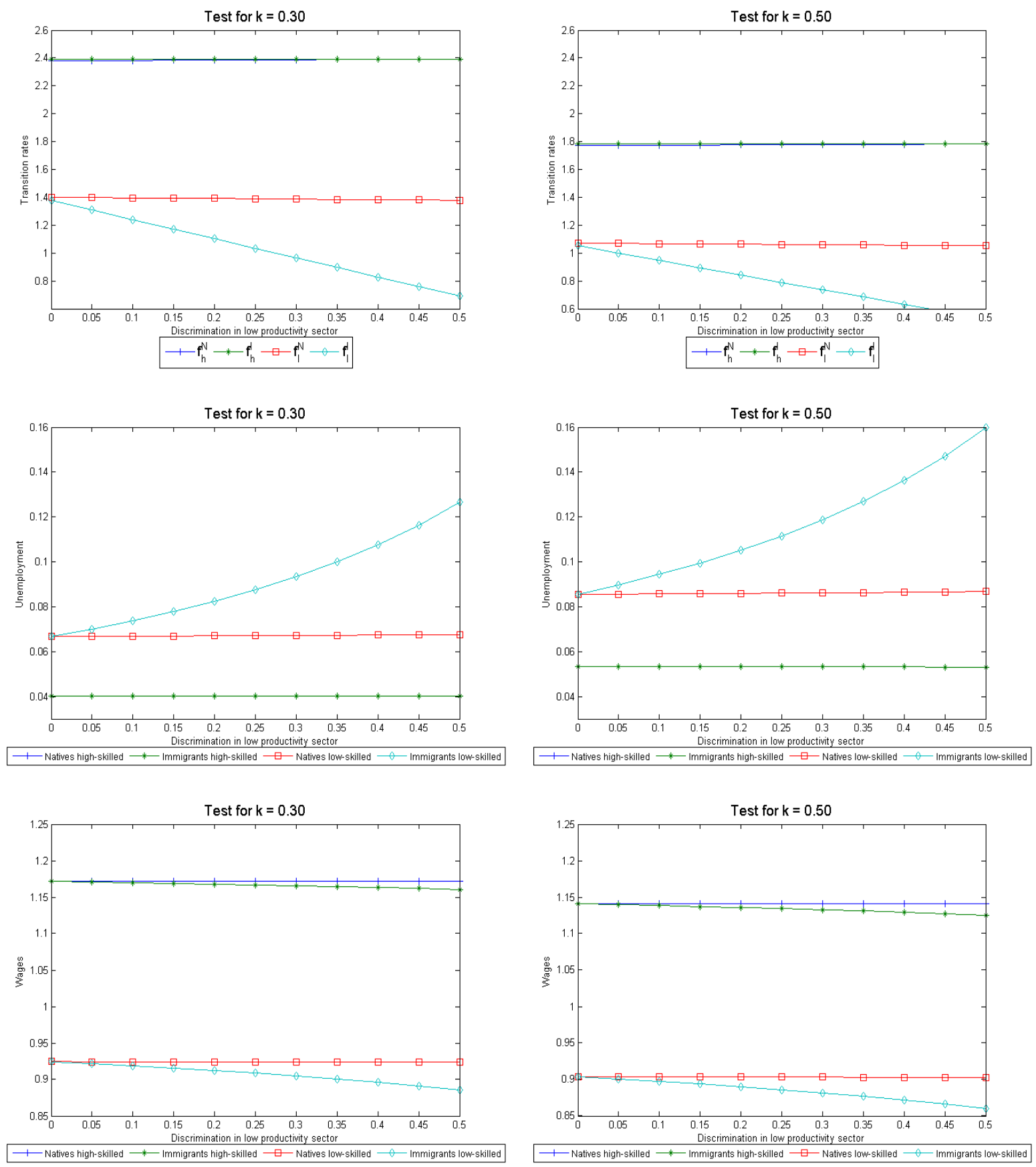

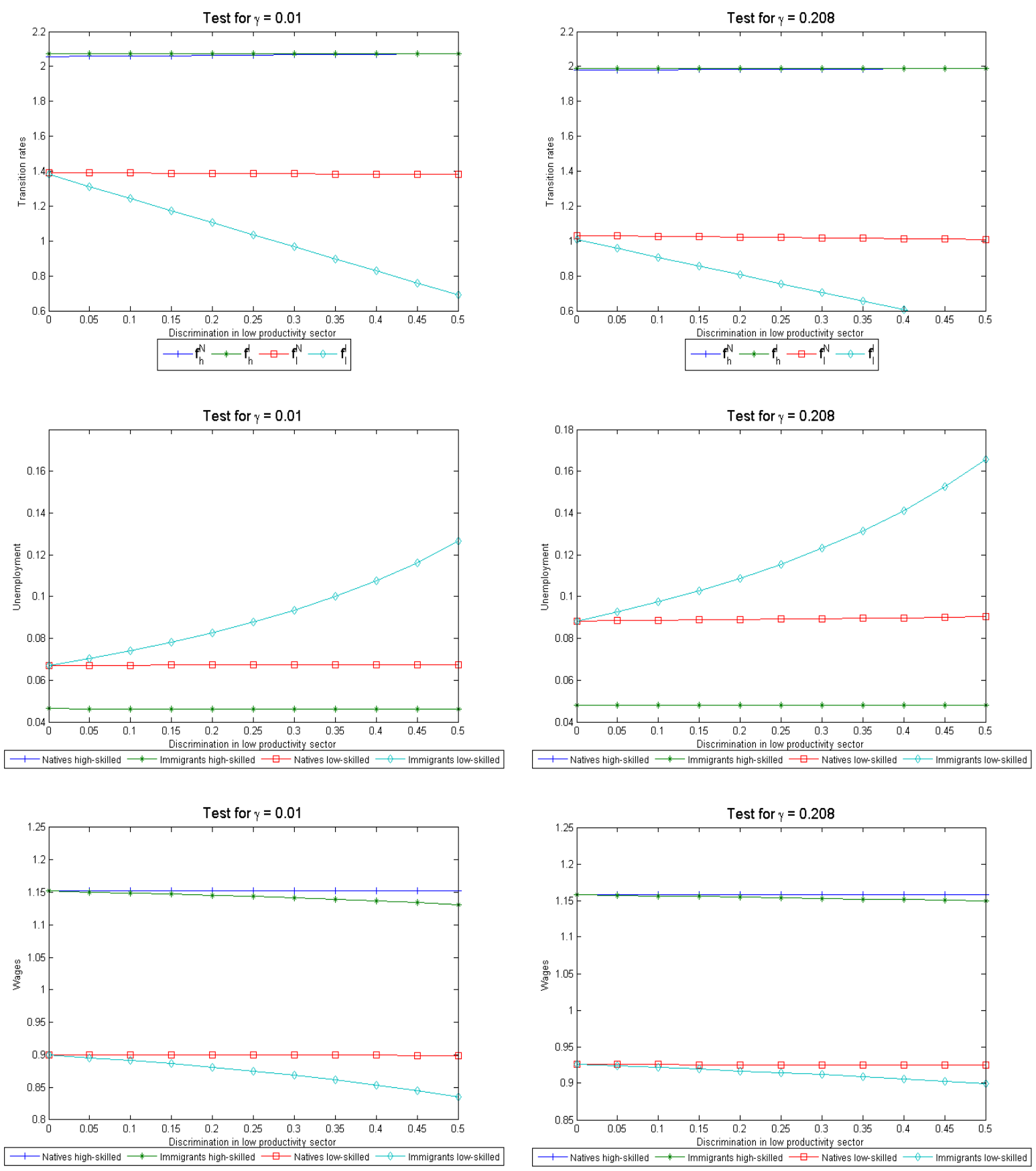

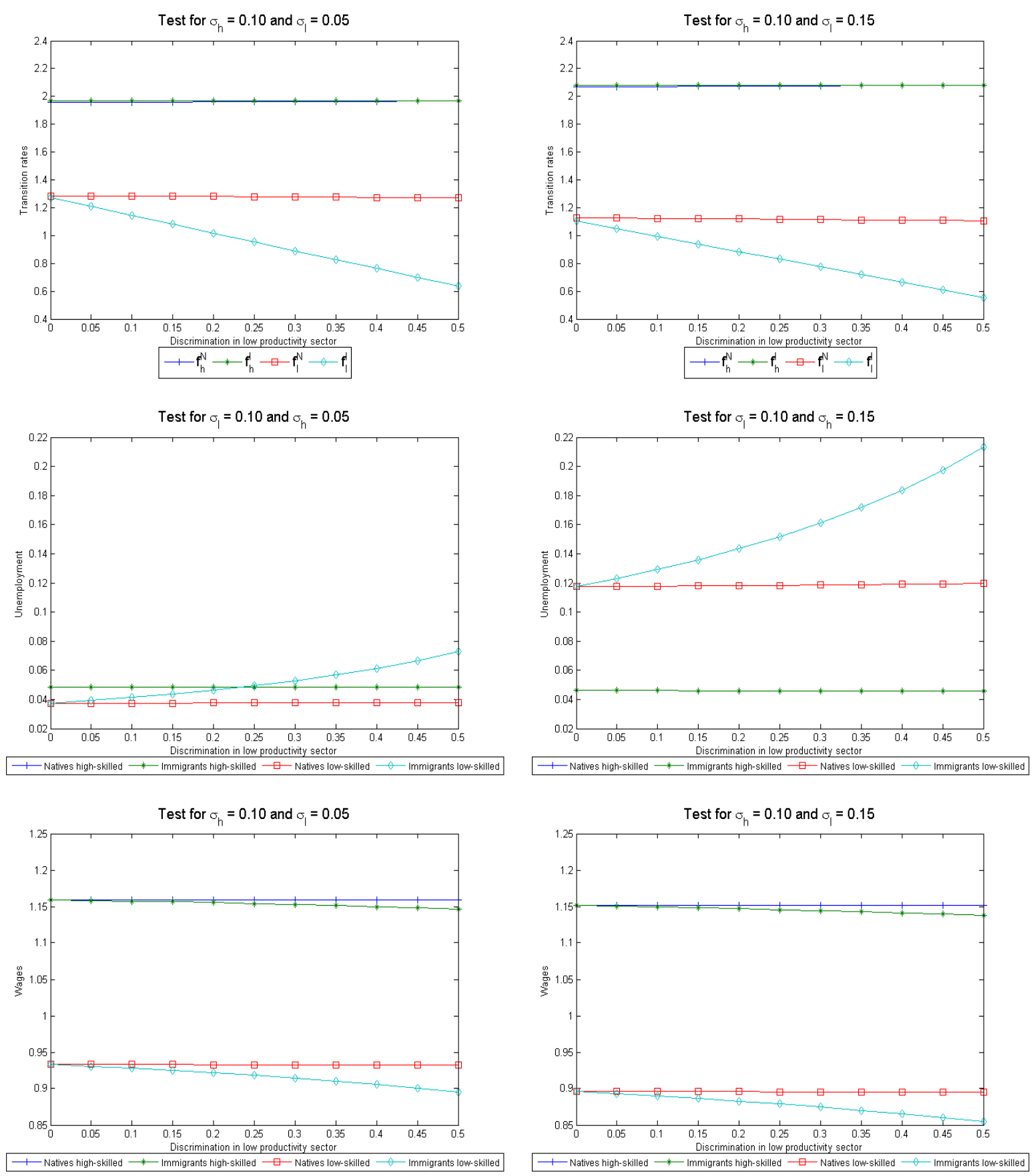

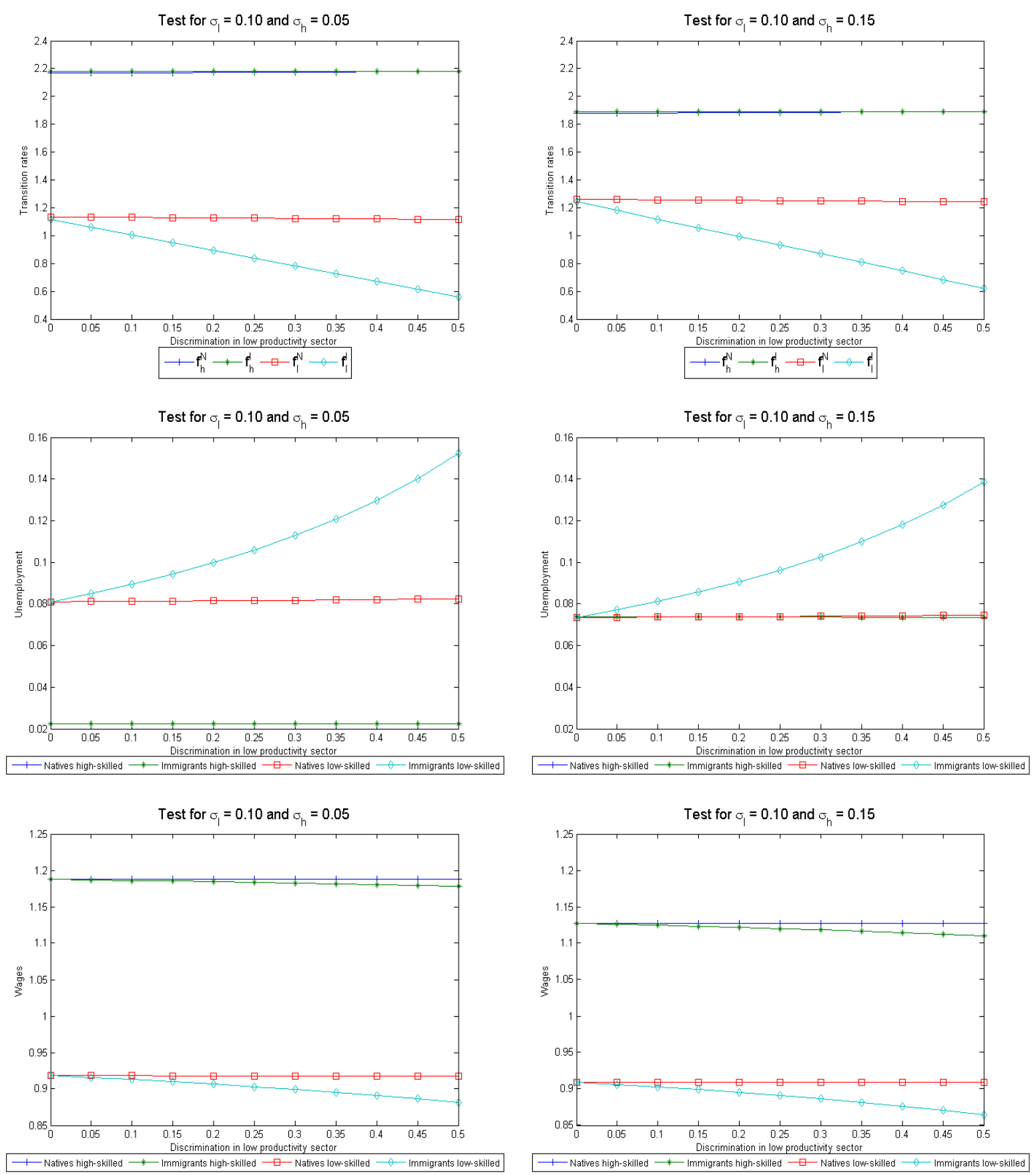
The next 36 figures consider case 2 where $d_{h}=d_{l}=0.00-0.50$
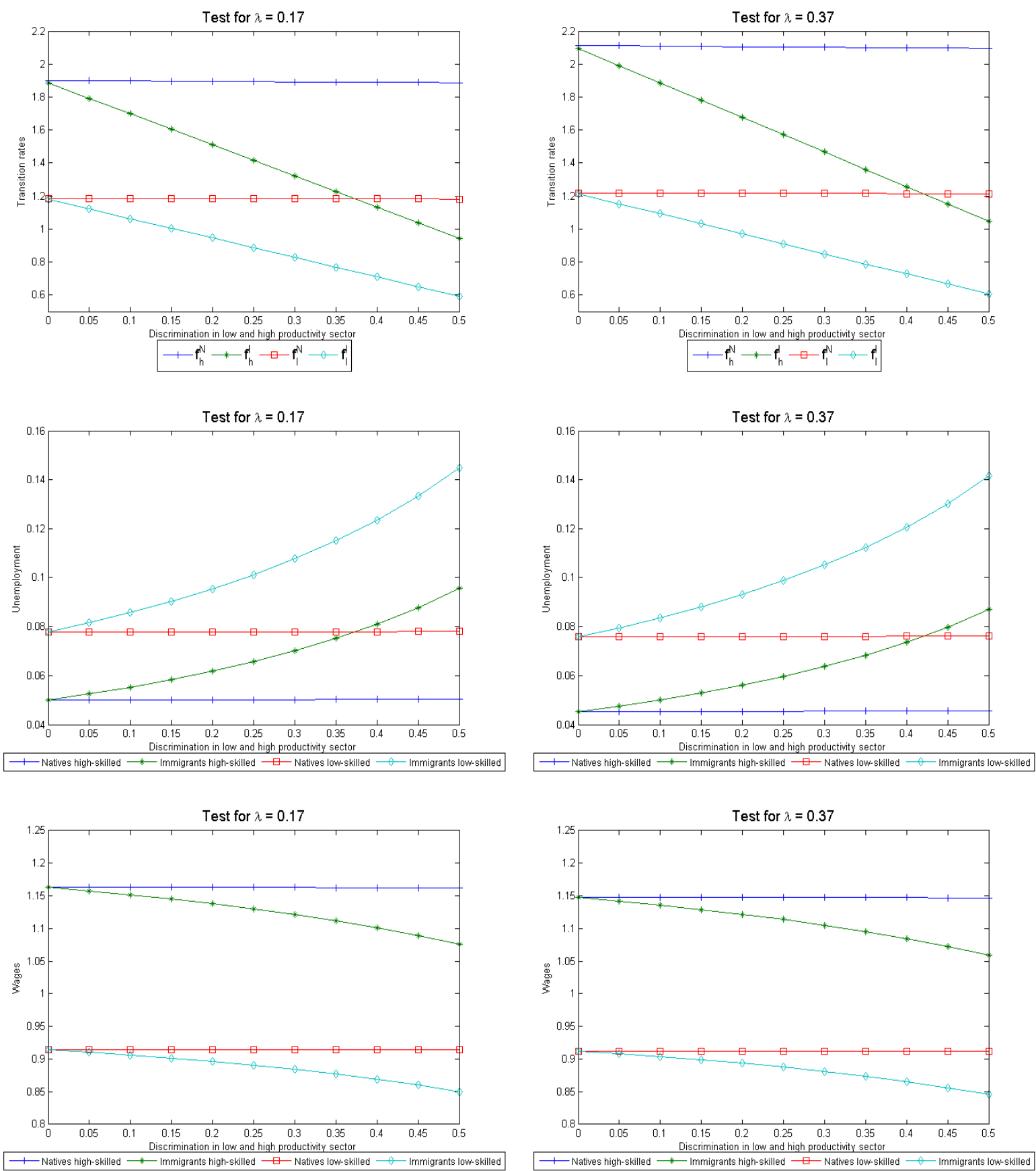

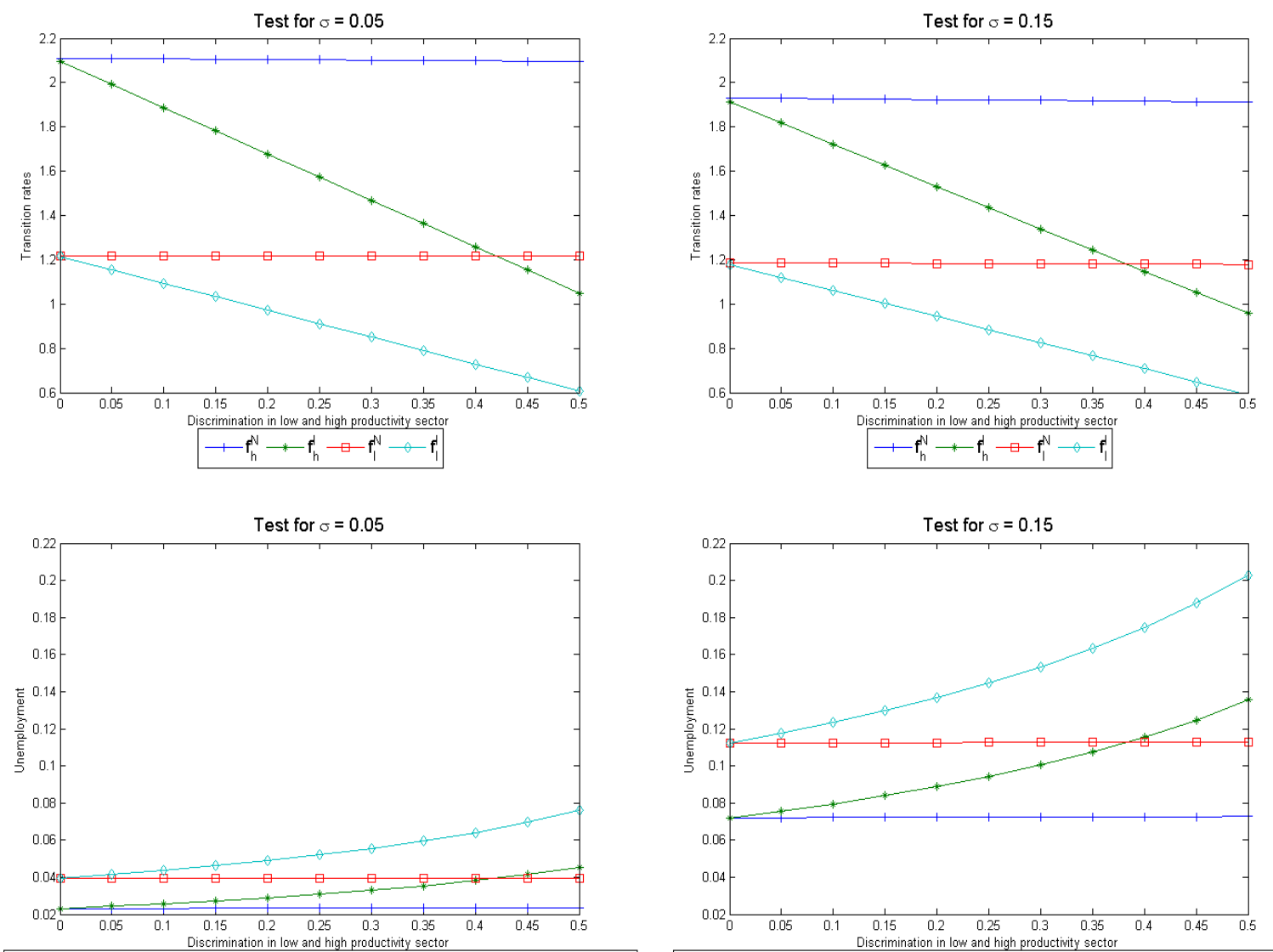

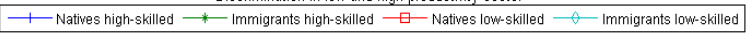
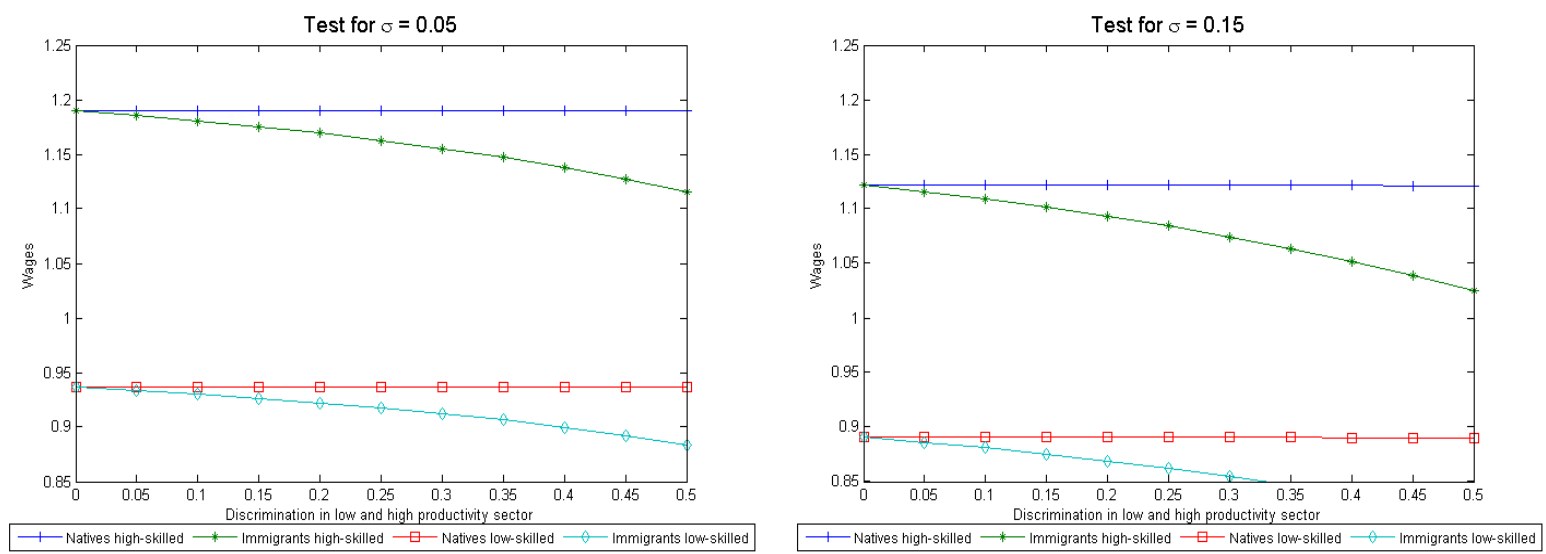

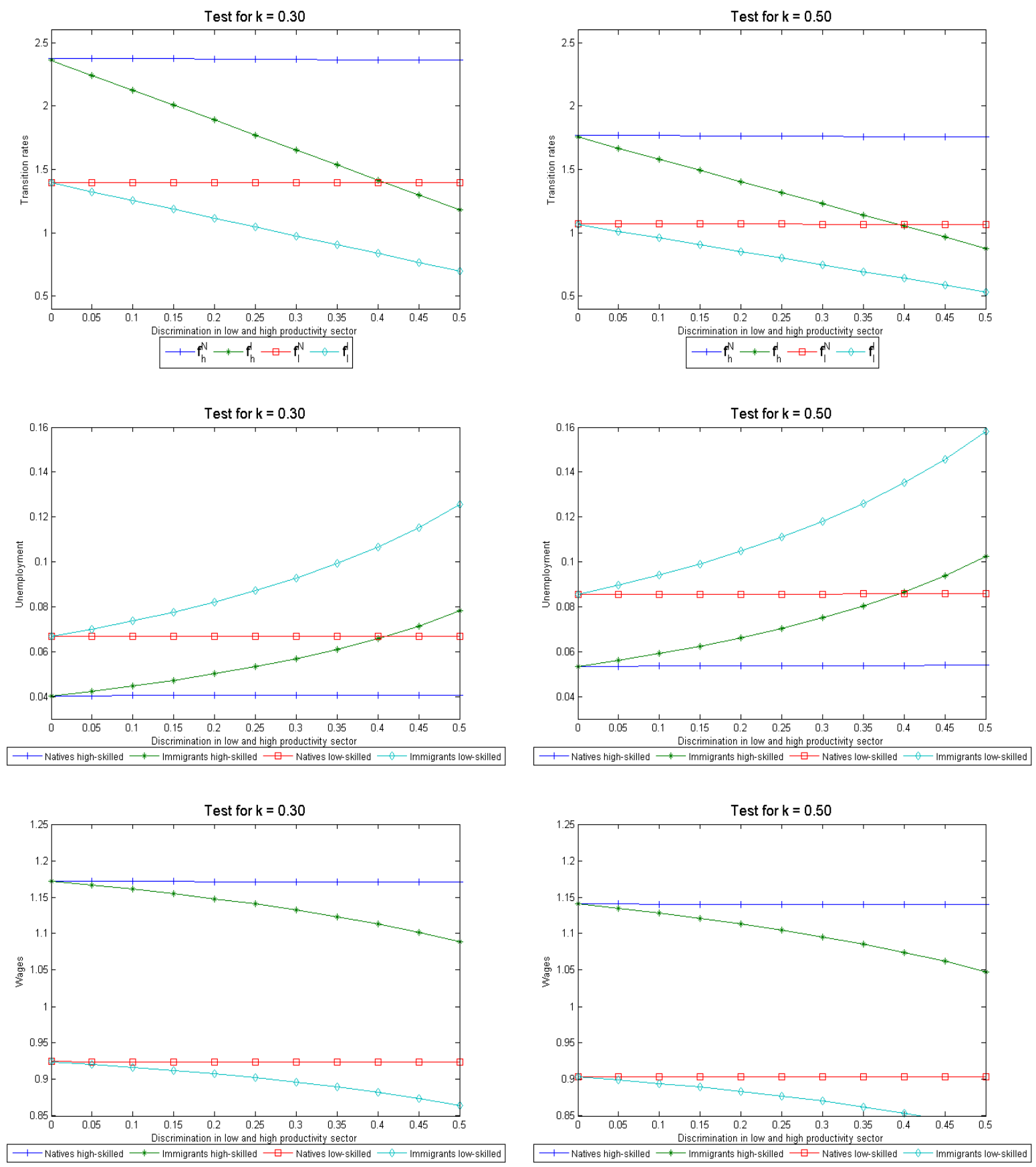

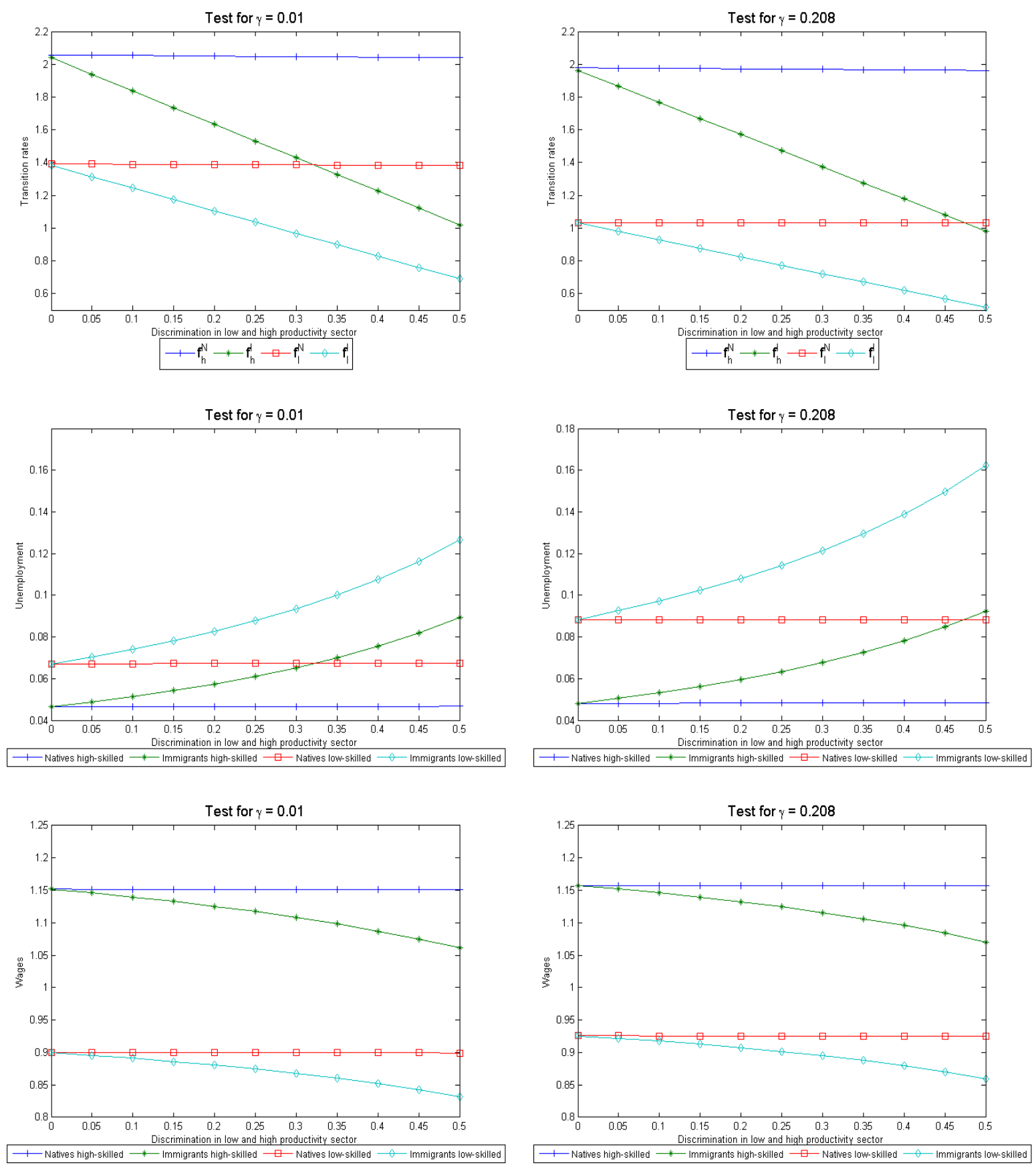

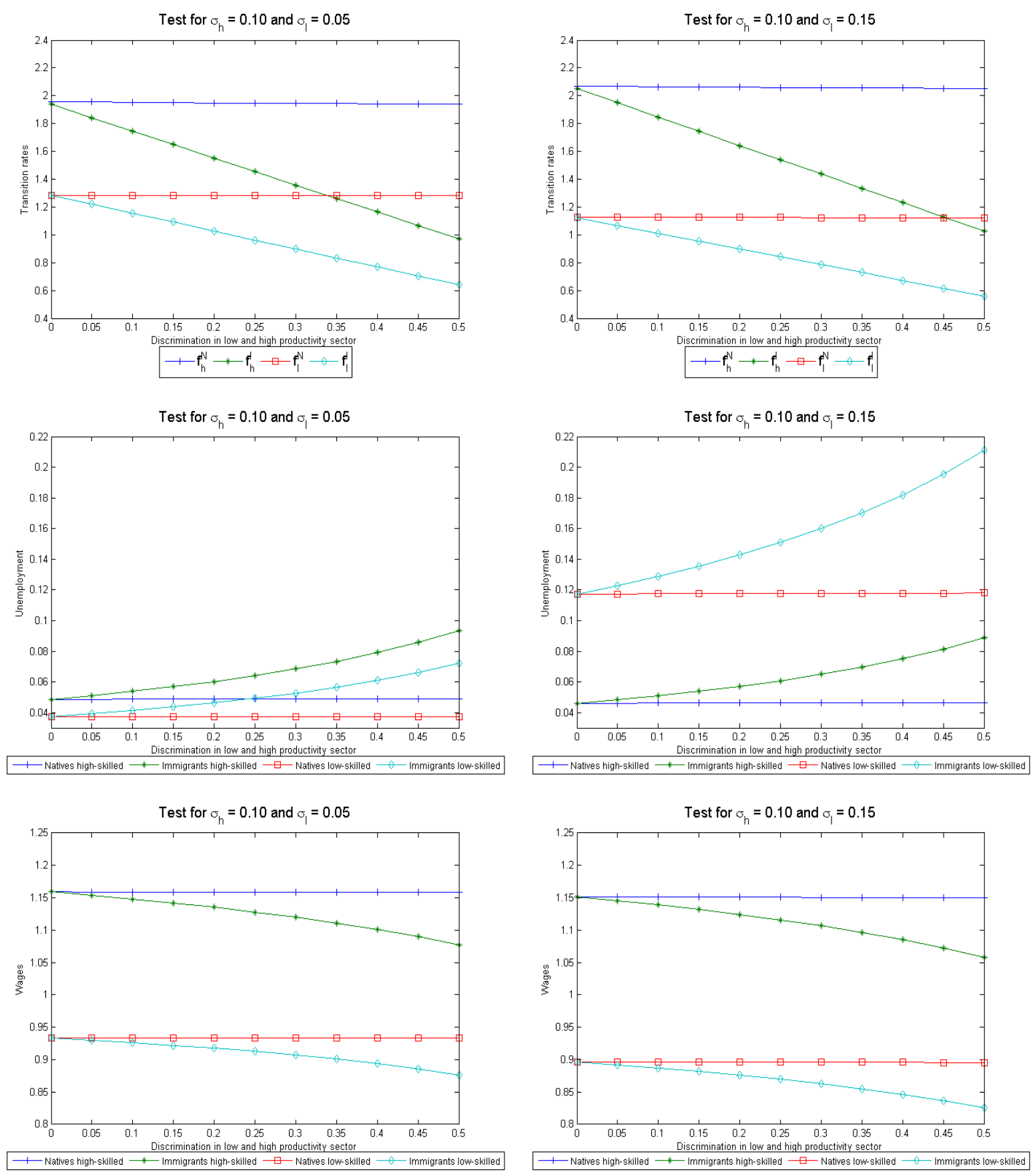

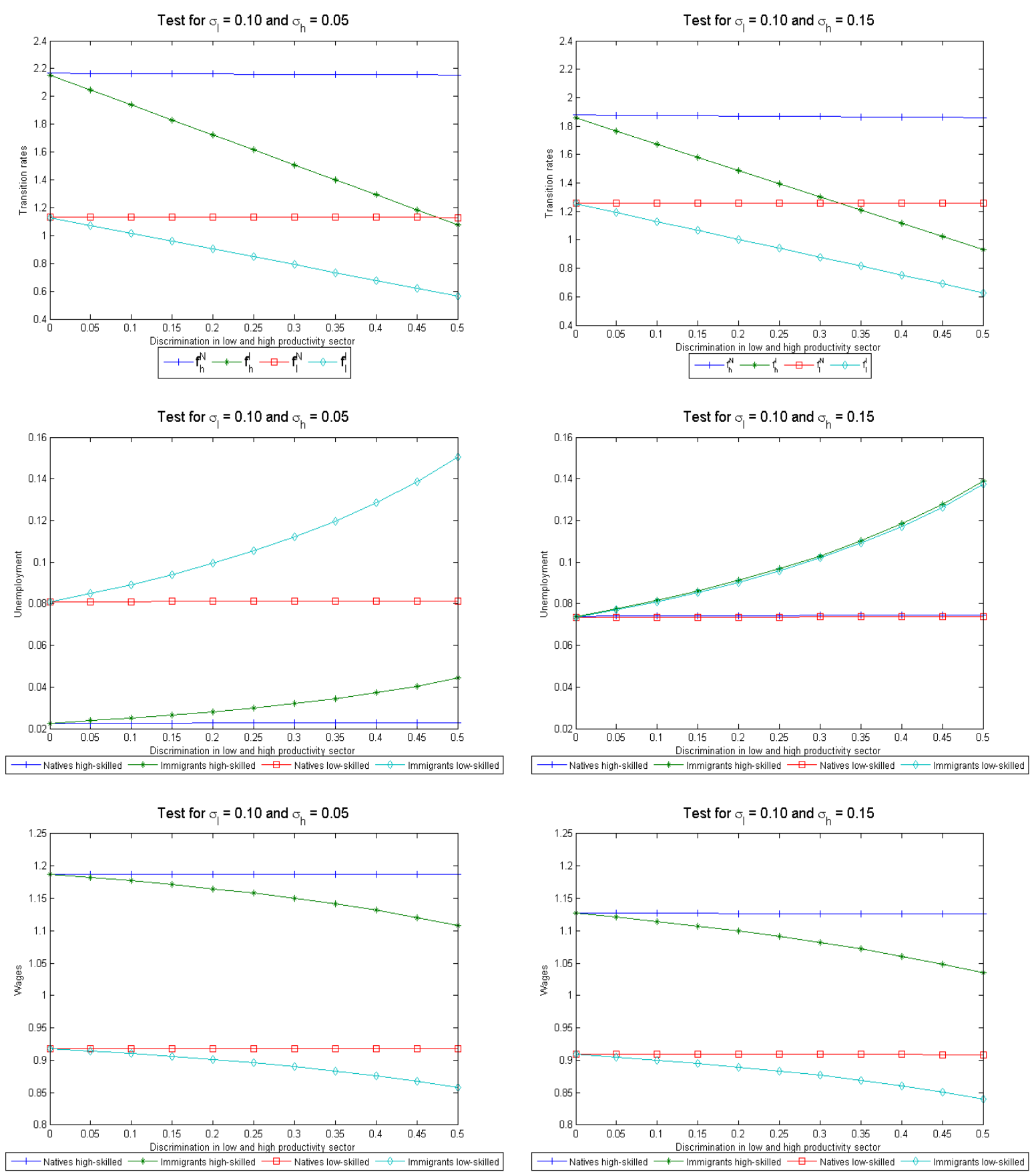